\title{
Propuesta de aplicación de la teoría CRM en las unidades productivas y comerciales del sector de confecciones y prendas de vestir en el emporio comercial de Gamarra, en Lima-Perú
}

\author{
Jorge Luis Escalante Flores \\ Doctor en Administración, Universidad Nacional Federico Villarreal Lima-Perú. \\ Magíster en Administración, Universidad del Pacífico Lima-Perú. \\ Bachiller y Licenciado en Administración, Universidade Federal do Rio Grande do Sul Brasil \\ Profesor de la Facultad de Administración y Contabilidad de la Universidad del Pacífico, Lima-Perú
}

\section{Resumen}

Las transformaciones sociales, la evolución de la ciencia y tecnología, la globalización, así como las concepciones modernas de la administración que se vienen dando en el siglo XXI, obligan a todas las organizaciones del mundo a innovarse de acuerdo con esta nueva realidad. La Plaza Gamarra no puede estar ajena a estos cambios y requiere confrontar esta realidad, adecuándose organizacional, administrativa y funcionalmente a los nuevos retos.

La micro y pequeña empresa, ubicada en la Plaza Gamarra, evidencia su constante preocupación por medio de su orientación a las diversas necesidades de los consumidores, su capacidad creativa para responder a los rápidos cambios del entorno y su capacidad de innovación tecnológica, que permiten responder a las demandas de los mercados interno y externo.

El presente trabajo de investigación trata de orientar la implementación de la teoría CRM en la Plaza Gamarra, como respuesta a la creciente necesidad de las unidades productivas y comerciales de fortalecer las relaciones con sus clientes, al replantear los conceptos tradicionales del marketing y emplear los conceptos del marketing relacional.

Esta decisión se tomó luego de analizar varias posibilidades. Finalmente, se asumió el reto de desarrollar este artículo, que consideramos de gran envergadura en un sector dinámico de la economía y como este puede ser fuente de acumulación de riqueza, mejora de calidad de vida y de trascendencia como país.

Palabras clave: Micro empresa, pequeña empresa, marketing relacional, marketing, percepción, satisfacción, estrategias, micro segmentación, valor, cliente, unidades productivas y comerciales, Plaza Gamarra, CRM. 
Propuesta de aplicación de la teoría CRM en las unidades productivas y comerciales del sector de confecciones...

\section{Introducción}

En los últimos años, las pequeñas y microempresas han cobrado significativa importancia y participación en la actividad económica, lo cual se explica por la reducción del tamaño del Estado, los procesos de privatización y las fusiones. Como consecuencia directa de todos estos factores, se incrementa el desempleo.

Las micro y pequeñas empresas (Mype), en respuesta a este contexto y como estrategia de sobrevivencia familiar, incorporan a las personas desplazadas y las constituyen en unidades productivas. Según la Asociación de Pequeños y Medianos Industriales del Perú (Apemipe), representan el $45 \%$ del producto interno bruto (PIB) y el $75 \%$ de la población económicamente activa (PEA), es decir, 5,3 millones de puestos de trabajo.

El apoyo a la pequeña y micro empresa constituye, en la actualidad, una clave para el mejoramiento de los ingresos de amplios sectores de la población, tal como lo ha demostrado la experiencia internacional. A su vez, permite la inserción del grueso de los factores económicos en el proceso de modernización.

La pequeña y microempresa en el Perú representa el $99 \%$ de las unidades económicas con posibilidades de competitividad y dinamismo, por su enorme capacidad de adaptación para atender a segmentos específicos y diferenciarlos del mercado. Así como, por su flexibilidad frente a los cambios y a su capacidad de innovación tecnológica, que permiten responder a las demandas de los mercados interno y externo.

Por ello, los rasgos más esenciales de las Mype son: la flexibilidad, que les permite orientarse hacia diversas necesidades de los consumidores, y su capacidad creativa, para responder a los rápidos cambios del entorno.

El significado social de las Mype se traduce en la generación de oportunidades de trabajo, que constituye la posibilidad de realización personal para millones de personas y, además, la promoción del desarrollo regional para los pueblos. Las Mype proveen de empleo a tres de cada cuatro peruanos.

Estas unidades económicas forman, de manera espontánea, aglomeraciones empresariales con elevados niveles de especialización y potencial competitivo. Existen alrededor de 3,3 millones de Mypes: 1,8 millones son urbanas y 1,5 millones, rurales (Gonzáles 2007: 22).

El nivel competitivo que existe en el sector comercio hace que muchas unidades productivas y comerciales busquen la especialización del servicio en determinados mercados.

El rubro de la pequeña y microempresa constituye uno de los mercados emergentes más importantes de la región, por su potencial como generador de empleo, fuente de producción y de ingresos. En la actualidad, se está tomando conciencia de su importancia en la economía de los países.

Se estima que las empresas que ocupen entre diez o menos trabajadores representarán más del $80 \%$ del total de compañías establecidas en la región latinoamericana. Como fuente de empleo, el Banco Interamericano de Desarrollo considera que en la región hay más de 50 millones de microempresas que emplean a más de 150 millones de personas (Cabal 2003).

Las Mype representan uno de los bastiones de la economía de los países latinoamericanos. Nuestras empresas y empresarios se caracterizan por su ingenio, su creatividad y por su inmensa capacidad para solucionar problemas. La micro y pequeña empresa tiene una importancia muy grande en el desarrollo de los países.

En México, el 98\% de las empresas son micros o pequeñas frente al $0,66 \%$ de las grandes empresas, y constituyen la base fundamental de la economía de la mayor parte de la población. Representan casi el $70 \%$ de las fuentes de empleo en el país azteca (Cabal 2003). 
Propuesta de aplicación de la teoría CRM en las unidades productivas y comerciales del sector de confecciones...

Las Mype representa más del $90 \%$ del total de las empresas italianas y cuentan con alrededor del $82 \%$ de los trabajadores italianos. Asimismo, el $60 \%$ de ellas tiene menos de 20 trabajadores o empleados. Además, este sector incide en el 70\% del PIB italiano (Cabal 2003). En Argentina, las micros y pequeñas empresas generan el $78 \%$ de empleo y el $61 \%$ del valor bruto de la producción. (Cabal 2003).

La existencia de alrededor de 1,2 millones de micro y pequeñas empresas, que ocupan a 3 millones de trabajadores, constituye un valioso capital y una gran oportunidad para Chile. Se adaptan con fluidez a las cambiantes condiciones del mercado; muestran un creciente proceso de bancarización y son buenos clientes del sistema financiero; colaboran con la generación de equidad en el proceso de desarrollo nacional; y destaca la creciente participación de la mujer en las empresas de menor tamaño (Cabal 2003). No obstante lo anterior, la micro y pequeña empresa participa solo con el 13\% del total de las ventas del país y contribuye con el $1 \%$ de las exportaciones.

En Venezuela, existen alrededor de 1.300.000 microempresas y unas 68.000 pequeñas y medianas empresas, de las cuales 56.000 son activas en comercio y servicio y 12.000 en manufacturas. Asimismo, las Mype generan el $77 \%$ del empleo (Cabal 2003). Es indudable que las micro, pequeñas y medianas empresas representan un pilar esencial de la sociedad venezolana.

En el Brasil, las micro, pequeñas y medianas empresas representan cerca del $98 \%$ del total de empresas, responden por cerca del $60 \%$ de los empleos generados y participan con el $43 \%$ de la renta total de los sectores industrial, comercial y de servicios. Además, cerca de $2 \%$ del total de las exportaciones del país corresponde a las micros y pequeñas empresas (Cabal 2003).

En Uruguay, las micro, pequeñas y medianas empresas representan el $99 \%$ de las unidades económicas productivas del sector privado. En el otro extremo, solo el $0,6 \%$ del tejido empresarial puede catalogarse como gran empresa (Cabal 2003).

En Colombia, las micro, pequeñas y medianas industrias (mpymes) representan más del 95\% de las empresas del país, proporcionan cerca del $65 \%$ del empleo y generan más del $35 \%$ de la producción nacional, lo que las convierte en motor fundamental para el desarrollo. En el caso del Ecuador, representan el $70 \%$ del empleo y el $80 \%$ del PIB (Cabal 2003).

Las experiencias internacionales muestran que en las primeras fases del crecimiento económico, las micro y pequeñas empresas desempeñan un papel fundamental. Su aporte, ya sea produciendo y ofertando bienes y servicios, demandando y comprando productos o añadiendo valor agregado, constituye un eslabón determinante en el encadenamiento de la actividad económica y la generación de empleo.

La importancia de las Mype en el desarrollo económico y social es un tema de reciente atención en América Latina por parte de los investigadores sociales, gobiernos y organismos internacionales. En la medida que se profundiza y se amplía el fenómeno de la globalización y de la liberalización comercial, mayores son los desafíos para los micro y pequeños empresarios peruanos en su inserción en el contexto internacional.

Diversos estudios realizados en América Latina, y en el Perú en particular, demuestran que la operatividad de las micro y pequeñas empresas constituye un fuerte impulso a la generación de empleo y al aumento de ingresos de amplios segmentos de la población, pues no solo constituyen un gran soporte en el desarrollo económico y social, sino que tienen un gran impacto en todo el territorio nacional.

Estas empresas son importantes porque apuntalan el crecimiento de los mercados y pueden ser un soporte activo en el éxito de los acuerdos bilaterales, regionales y multilaterales de libre comercio. Por su gran impacto en el desempeño económico y 
Propuesta de aplicación de la teoría CRM en las unidades productivas y comerciales del sector de confecciones...

social, valoramos la pertinencia y la necesidad de profundizar en el conocimiento de las micro y pequeñas empresas, pues su éxito es el éxito del país.

\section{Objetivo}

La presente investigación tiene como principal objetivo:

- Analizar y proponer las técnicas de fidelización pertinentes para los propietarios de las unidades productivas y comerciales de la Plaza Gamarra.

Además, como objetivos específicos se tienen los siguientes:

- Identificar y conocer las estrategias de mercadeo en la Plaza Gamarra practicados por las unidades productivas y comerciales.

- Identificar y comprender las percepciones de los clientes con respecto a los servicios ofrecidos en la Plaza Gamarra por las unidades productivas y comerciales.

- Identificar el nivel de satisfacción que tienen los clientes de los servicios en la Plaza Gamarra.

- Identificar los atributos más valorados por los clientes y microempresarios de Gamarra.

- Identificar las técnicas de fidelización más relevantes para aplicar en el emporio de Gamarra.

\section{Marco teórico}

El término Customer Relationship Management (CRM) es de origen inglés y se empezó a utilizar por primera vez en los Estados Unidos, a principios de los años 1980. Se suele traducir como administración al cliente, sistemas de información sobre el cliente, atención al cliente e incluso, concentración en el cliente y administración centrada en el cliente.

Se trata de una teoría joven, con un desarrollo científico relativamente reciente que está revolu- cionando la mercadotecnia y transformando modelos de negocios enteros. Cabe señalar que en la mayoría de los países se emplea su sigla CRM al hacer referencia a esta teoría.

Una de las primeras definiciones procede de Berry (1983, traducción del autor), quien considera que el marketing relacional consiste en «atraer, mantener e identificar las relaciones con los clientes».

Una de las definiciones más reconocidas la aporta Gronroos (1996). Desde una perspectiva relacional, define el marketing como «el proceso de identificar y establecer, mantener y acrecentar, relaciones beneficiosas con los clientes y otros agentes implicados. Esto se realiza por medio de la mutua entrega y cumplimiento de promesas» ${ }^{1}$.

Respecto de la definición de Customer Relationship Management, el Dr. Stanley Brown manifiesta que es «una estrategia de negocios que busca conocer, prever y administrar las necesidades de los clientes reales y potenciales de una organización».

Esto implica la adquisición y aplicación de conocimientos sobre los clientes; así como, el empleo de esta información en los diversos puntos de contacto con el cliente para equilibrar ingresos y utilidades, para lograr su máxima satisfacción.

Sin embargo, el CRM es una estrategia que debe ajustarse a cada segmento de mercado. Es en ello, justamente, donde residen el desafío y la oportunidad.

Según Gronroos (1996), para ser eficaz en la administración de sus relaciones con los clientes, una organización debe:

- Definir su estrategia de clientes. Esto requiere el conocimiento de los segmentos de los clientes y sus necesidades. Se trata de un requisito obligatorio para saber qué productos y servicios ofrecer, y si tal ofrecimiento responderá estrictamente a las exigencias de cada segmento.

1. Traducción del autor. 
- Formular una estrategia de canal y producto. Bajo este enfoque se define la vía de la que hará uso la organización para distribuir sus productos y servicios en forma eficiente y eficaz, con el fin de garantizar la productividad de ventas y la efectiva administración del canal.

- Comprender la importancia de una estrategia de infraestructura robusta e integrada. Implica crear un entorno que facilite la relación con el cliente y permita satisfacer sus necesidades. En ese sentido, es necesario contar con la capacidad de lograr una administración proactiva de clientes y una atención reactiva al cliente.

Hoy, el concepto académico del CRM incluye las siguientes ideas fundamentales: el conjunto de actividades dirigidas hacia el establecimiento, desarrollo y mantenimiento de relaciones de intercambio exitosas; así como la comprensión, explicación y gestión de relaciones de colaboración en los negocios entre proveedores y clientes (véase el gráfico 1).
El punto focal del CRM se centra, principalmente, en la gestión de la relación entre la empresa y sus clientes. Sin embargo, para facilitar el éxito de esta gestión, se considera que otros agentes del mercado pueden estar implicados, tales como: proveedores, distribuidores, socios, instituciones financieras, etcétera.

El cumplimiento de las promesas debe constituir también una parte importante de las responsabilidades del marketing, ya que este cumplimiento constituye un medio para lograr la satisfacción del cliente, su retención y, a largo plazo, la rentabilidad.

Desde el punto de vista del CRM, el valor es considerado como un componente esencial para obtener y mantener una ventaja competitiva sostenible. En efecto, la obtención de buenos resultados está estrechamente relacionada con la capacidad de la firma de generar confianza con sus clientes y de retenerlos.

\section{Gráfico 1}

Perspectiva del Customer Relationship Management

\section{Corrientes de Investigacion}
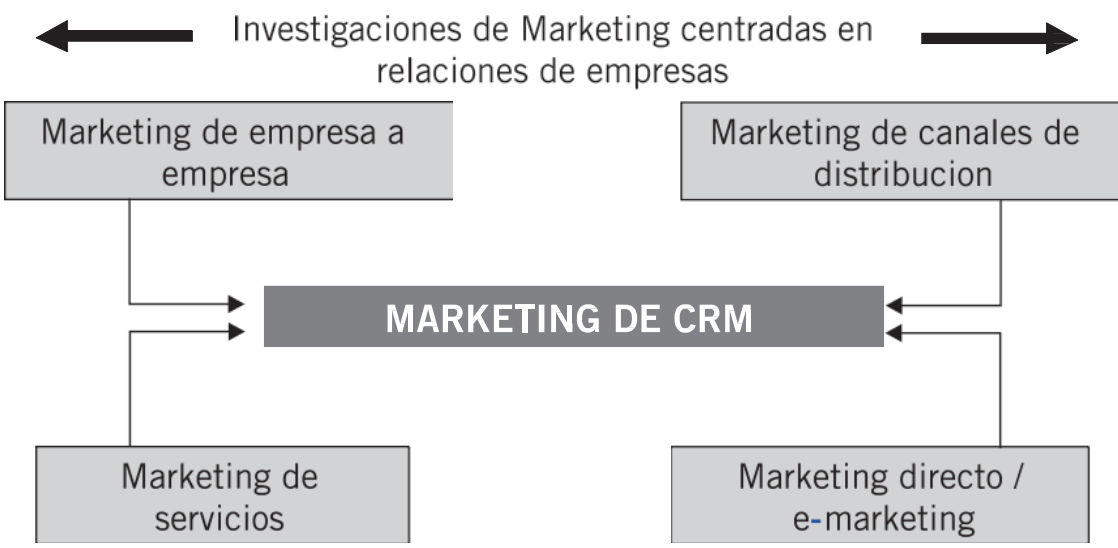
Propuesta de aplicación de la teoría CRM en las unidades productivas y comerciales del sector de confecciones...

El punto focal del CRM se centra, principalmente, en la gestión de la relación entre la empresa y sus clientes. Sin embargo, para facilitar el éxito de esta gestión, se considera que otros agentes del mercado pueden estar implicados, tales como: proveedores, distribuidores, socios, instituciones financieras, etcétera.

El cumplimiento de las promesas debe constituir también una parte importante de las responsabilidades del marketing, ya que este cumplimiento constituye un medio para lograr la satisfacción del cliente, su retención y, a largo plazo, la rentabilidad.

Desde el punto de vista del CRM, el valor es considerado como un componente esencial para obtener y mantener una ventaja competitiva sostenible. En efecto, la obtención de buenos resultados está estrechamente relacionada con la capacidad de la firma de generar confianza con sus clientes y de retenerlos.

\section{Objetivos del CRM}

Según Brown (2001: 34), los objetivos del CRM son los siguientes:

a. Incrementar las ventas, tanto por el incremento de las ventas de clientes actuales como por ventas cruzadas

El mantenimiento de una relación continua, interactiva y dinámica con los clientes solo puede mantenerse si está sustentada por una amplia plataforma de servicios de apoyo que se prestan antes, durante y después de la venta. De ahí, el factor de crecimiento potencial del volumen de negocios.

Sin perder el «posicionamiento», la empresa puede ofertar (fundamentalmente con base en alianzas estratégicas) una amplia gama de servicios, apoyándose en su credibilidad y «buenas relaciones» con los clientes.

b. Maximizar la información del cliente

Toma en cuenta una relación continuada con los clientes al multiplicar las ocasiones en que se establece algún tipo de contacto entre ellos y la empresa. La finalidad es lograr que las empresas que han adoptado el enfoque relacional estructuren las relaciones de tal forma que esos contactos se produzcan de forma continua y prolongada.

Brown (2001) también manifiesta que el sistema de información del marketing relacional opera mediante la integración y gestión armónica, interactiva e interdependiente de las tres vertientes señaladas: creación, mantenimiento y gestión de las relaciones con los clientes, conforme se puede apreciar en el gráfico 2 .

c. Identificar nuevas oportunidades de negocio Está ligado estrechamente con el factor tiempo. Es fundamental que la organización llegue oportunamente al que la necesite, para permitirle adoptar las medidas de acción; caso contrario, carece de valor, pues puede impedir que se alcancen los resultados deseados.

d. Mejora del servicio al cliente

Las actividades relacionadas con el servicio no pueden realizarse en forma rígida y encuadrada en reglas fijas. Las personas y organizaciones que conforman el «Sistema de Servicio al Cliente» deben estar en condiciones de adaptarse a estos cambios, adoptando los procedimientos más convenientes para no disminuir su eficacia.

e. Procesos optimizados y personalizados Está ligado estrechamente a la redefinición de los procesos para optimizar las relaciones con los clientes, consiguiendo procesos más eficientes y eficaces.

Este objetivo incluye los siguientes conceptos:

- Tecnología. Que nos permite dar sustento al nuevo modelo de negocios y desarrollar una infraestructura estratégica de uso eficiente de la información. La búsqueda de la tecnología brinda una plataforma para la conversión de datos en conocimiento. Además, se debe hacer un análisis previo de la inversión y un seguimiento de sus resultados. 
Propuesta de aplicación de la teoría CRM en las unidades productivas y comerciales del sector de confecciones...

Gráfico 2

Estructuración de una visión integral de información

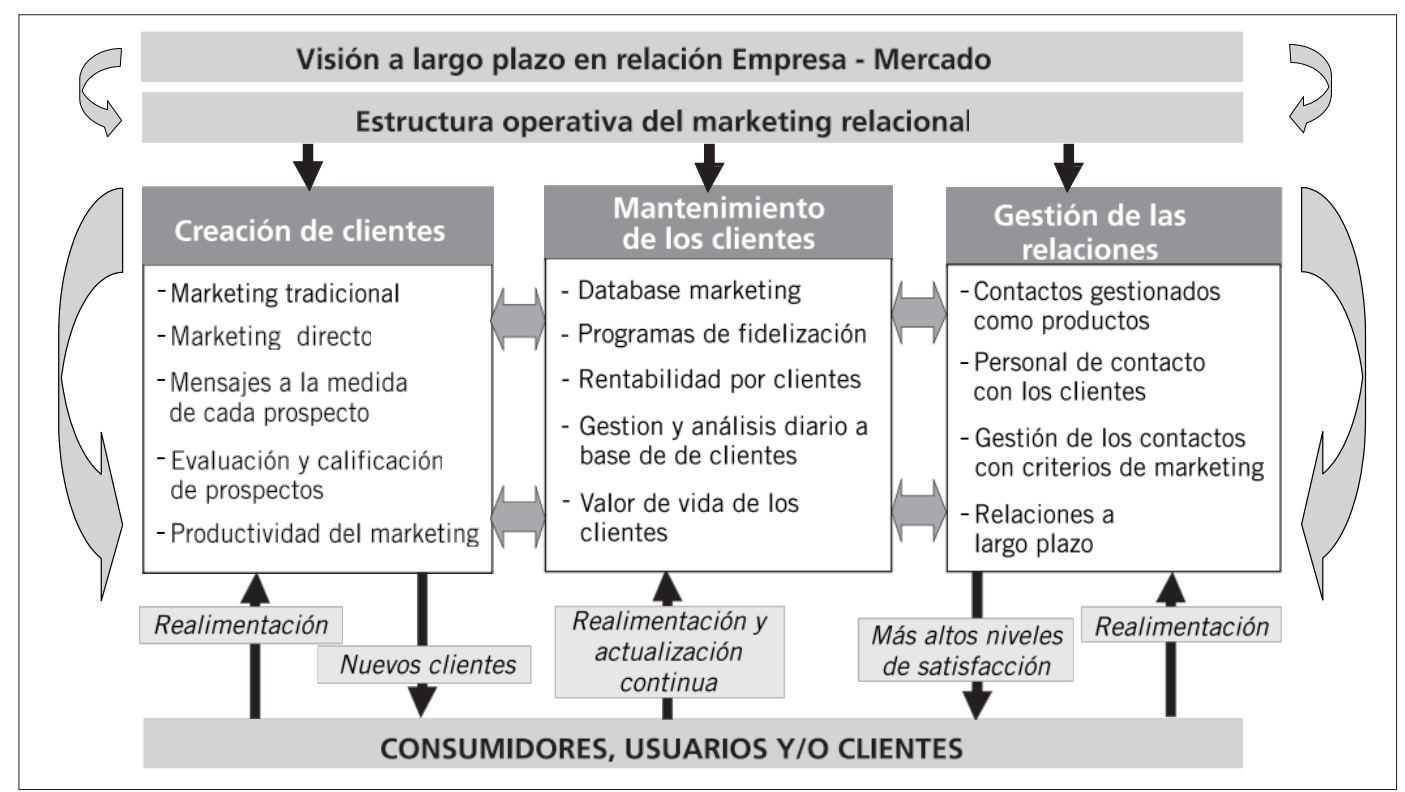

Fuente: Brown 2001: 68

- Capacidad de respuesta. Es el trabajo de dar respuesta al contenido de la información sobre los clientes, lo cual se traduce en que la organización es capaz de iniciar las acciones correctas en áreas como: desarrollo de servicios adaptados a las necesidades de los clientes; innovación constante del portafolio de servicios; mayor rapidez que la competencia para responder a los cambios del mercado; desarrollo de planes y estrategias de mejora que respondan a la perfección a los requerimientos de los clientes; ofrecer información amplia y precisa a los clientes sobre los productos y servicios de la empresa; rápida capacidad de reacción ante las acciones de la competencia.

- Creación de valor. Trabajar activamente en la mejora continua de los servicios de la organización. La finalidad se orienta a satisfacer las necesidades y superar las expectativas de los clientes, conforme se aprecia en el gráfico 3.

Gráfico 3

Perspectiva de la cadena de valor

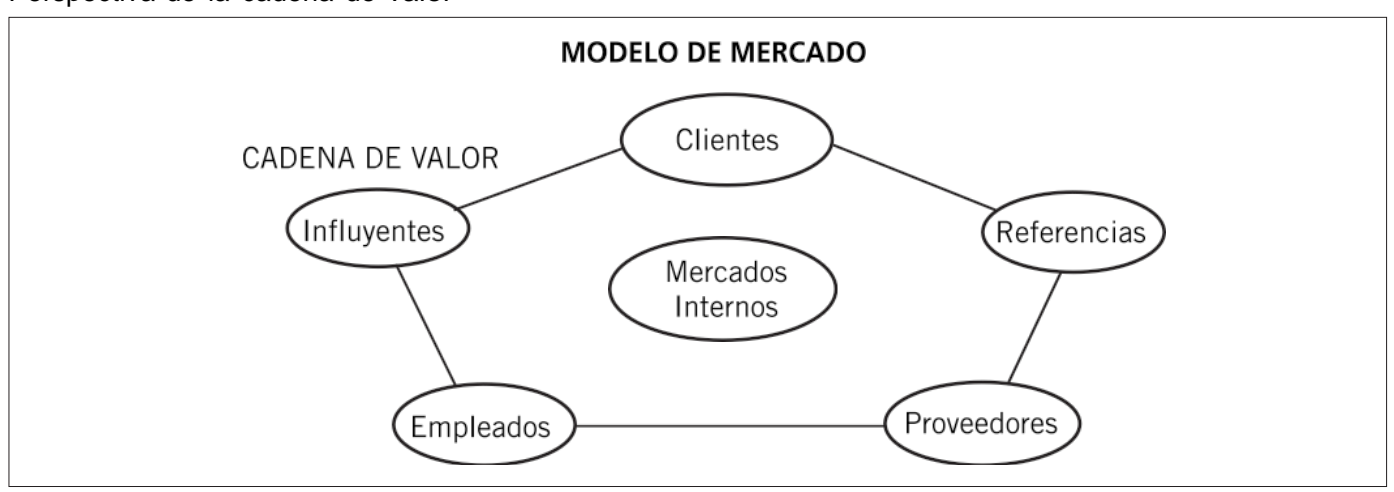

Fuente: Brown 2001: 105 
Propuesta de aplicación de la teoría CRM en las unidades productivas y comerciales del sector de confecciones...

f. Mejora de ofertas y reducción de costes Proporciona innovación constante con el fin de satisfacer necesidades inesperadas, batir a los competidores o explotar nuevas oportunidades; así como, conocimiento permanente del comportamiento y las necesidades del cliente para adoptar la oferta. La relación del desempeño y la consecución de resultados al establecer costes más bajos facilitan una más alta participación de mercado. En la medida que los clientes conocen mejor el producto o servicio, se convierten en consumidores o usuarios más eficientes, lo que implica que requieran menos ayuda en el proceso de compra. Esto representa un ahorro de tiempo y costes para la empresa.

g. Identificar a los clientes potenciales que mayor beneficio generan a la empresa Establece la realización de un análisis estadístico del valor individual de un cliente (su tamaño e importancia relativos en el mercado), afinidad de la compañía (gustos y aversiones, participación de compras atribuibles a los competidores) y valor del período de vida (estimación del valor futuro del cliente). Sobre la base de los resultados, la organización ajusta sus productos y servicios para satisfacer las necesidades de los segmentos más redituables y formula estrategias para la adquisición de nuevos clientes (la retención y realización de ventas cruzadas a los existentes y la consolidación de su lealtad).

h. Fidelizar al cliente, mediante el incremento de las tasas de retención de clientes

Proporciona la conservación de la clientela adquirida y su desarrollo para fidelizar una base de clientes, consumidores o usuarios suficientemente amplia como para generar los recursos que le permitirán cubrir sus costes e invertir en su propio desarrollo y progreso. Así como, en el de todos aquellos que forman parte de ellas.

\section{Características del CRM}

Respecto de las características del CRM, Brown (2001: 36) manifiesta que son las siguientes:

\section{- Enfoque al cliente}

Se orienta a la filosofía del marketing relacional; es decir, a la atracción, desarrollo y retención de relaciones con los clientes. Bajo esta perspectiva, las actividades del marketing tradicional, centradas fundamentalmente en la captación de clientes, son solo una parte del marketing relacional, ya que este enfoque propugna además el mantenimiento y consolidación de las relaciones con los clientes a lo largo del tiempo.

- Inteligencia de clientes

Enfatiza tener conocimiento sobre el cliente para poder desarrollar productos y/o servicios enfocados a sus expectativas. Para transformar la información disponible en conocimiento útil para el negocio se emplean bases de datos, que permitirán el descubrimiento y la cuantificación de relaciones predictivas.

- Interactividad

Se relaciona con el proceso de comunicación entre la empresa y el cliente. Debido a las pobres comunicaciones que se establecen con los clientes, muchas veces estos exageran las deficiencias que existen en la calidad percibida. Incluso, estas se perciben antes de obtener el producto o recibir el servicio.

- Fidelización de clientes

Enfocada en desarrollar y mantener relaciones continuadas con los clientes, siempre bajo la premisa de que dicha relación proporciona valor para todos los actores implicados en ella.

- Personalización

Mediante las comunicaciones y ofertas personalizadas con el cliente, para lo cual se necesitan grandes esfuerzos en inteligencia y segmentación de clientes. La personalización del mensaje aumenta drásticamente la eficacia de las acciones de comunicación.

\section{Tipos de CRM}

La aplicación de la teoría CRM permite a la compañía dirigirse a todos los tipos de clientes que sirve en diferentes momentos de su ciclo de vida como tales. Así como, dirigir el programa de mercadotecnia más acorde con la actitud de un cliente respecto de la compañía y con la disposición 
Propuesta de aplicación de la teoría CRM en las unidades productivas y comerciales del sector de confecciones...

de aquél a comprar los productos y servicios de estas.

En relación con los tipos de programas de CRM, Brown (2001: 38) manifiesta que existen las siguientes: permiten a una compañía recuperar a clientes que ya han desertado o planean hacerlo, generar lealtad entre clientes existentes, realizar ventas ascendentes o cruzadas a estos clientes y buscar nuevos clientes potenciales.

- Recuperar o conservar

Se orienta a convencer a un cliente de seguir siéndolo en el momento en que considera la posibilidad de prescindir del servicio o en convencerlo de volver a serlo, si ya ha abandonado la organización.

- Prospección

Se relaciona con el intento de conseguir nuevos clientes, mediante el desarrollo de un eficaz modelo de segmentación sobre la base de necesidades, que permita a la organización el eficiente direccionamiento de la oferta.

- Lealtad

Para evitar la defección de sus clientes, las organizaciones emplean tres elementos esenciales: segmentación basada en el valor, segmentación basada en necesidades y modelos predictivos de cambio de marca.

La segmentación basada en el valor permite a la organización determinar cuánto está dispuesta a invertir en la retención de la lealtad de un cliente.

La organización puede servirse de la segmentación basada en necesidades para determinar un programa personalizado de lealtad. El modelo predictivo de cambio de marca se orienta a pronosticar el desgaste de la preferencia de los clientes, elaborado a partir de los abundantes datos demográficos e historia del índice de uso de la base existente de clientes.

- Ventas cruzadas/ascendentes

Es decir, el monto que gasta el cliente en la realización de compras a la organización. El propósito es identificar ofertas complementarias que podrían ser del agrado de un cliente. Las campañas de venta cruzada/ascendente son importantes porque los clientes objetivo ya sostienen una relación con la organización. Por lo tanto, es poco probable que conciban la oferta como una mercancía genérica y estén dispuestos a pagar un alto precio por ella.

\section{Principios del CRM}

Gronroos (1996: 55) manifiesta que para ser eficaz en la administración de sus relaciones con los clientes, una organización debe aplicar los siguientes principios:

- Establecimiento de metas precisas

Al agregar valor al diseño y sostenimiento de la iniciativa, se establece la participación permanente de los individuos (gerencia media, alta dirección y empleados de primera línea) al logro de objetivos. La finalidad es que toda actividad de CRM debe complementarse con metas concretas, que sirvan como referencia durante el proceso de implantación. Es decir, es necesario garantizar que el sistema sirva de apoyo a las estrategias de clientes, canales y productos.

- Participación de todos los departamentos afectados

En todos los niveles, es indispensable la participación activa de los jefes de los departamentos afectados con la implantación, mediante la distribución de responsabilidades, la regulación de todas las actividades y la cobertura apropiada, para evitar omisiones y duplicidad de esfuerzos.

- Uso de los mejores empleados de la empresa En toda actividad de CRM, es necesario involucrar a los empleados que mejor conozcan la compañía; es decir, a los expertos de negocios que contribuirán a definir sus procesos con los técnicos de CRM. La ventaja de la participación de los empleados como responsables de procesos es responder a los requerimientos diarios de los usuarios del sistema. Aquí quedan comprendidos: cómo rastrear el tiempo de respuesta necesario, vistas de pantallas requeridas, informes producidos, etcétera.

- Influencia en la organización Para lograr sus objetivos, la organización requiere nuevas maneras de pensar. Estos son 
Propuesta de aplicación de la teoría CRM en las unidades productivas y comerciales del sector de confecciones...

elementos que, administrados correctamente, le permitirán o le facilitarán alcanzar sus objetivos. Bajo este rubro se listan la venta basada en equipos, coordinación de las actividades, intercambio de información de la fuerza de ventas, etcétera.

- Coordinación con otras iniciativas de la empresa

Proporciona coordinación y retroalimentación con las demás iniciativas, para lo cual es necesario incluir a todas las personas involucradas. Facilita la participación permanente del departamento de tecnología de información, especialistas en procesos y la alta dirección, los que trabajarán en conjunto.

- Consideraciones de interfaces, conversiones y transferencias de datos

Si los datos convertidos no están en orden o las interfaces necesarias no poseen suficiente capacidad, el sistema no cumplirá sus metas. En resumen, el aseguramiento de la calidad de la conversión de datos, así como la realización de las pruebas de interfaces, deben efectuarse en cada etapa del proceso.

- Participación de numerosos empleados

Se debe involucrar a la mayor parte de la organización, no solo a los responsables del proceso, pues la adaptación a los cambios inducidos por el CRM suele ser lenta. Brown (2001) manifiesta que para obtener resultados óptimos, es preciso conseguir la participación en el proyecto de alrededor de la tercera parte de los empleados. Esto generará un alto grado de aceptación y referencias futuras positivas.

- Búsqueda de un promotor

El proyecto precisa de un promotor cuyas metas personales estén directamente relacionadas con el éxito de la iniciativa. Además, el promotor contribuye a identificar los recursos y reducir la resistencia de los empleados. Asimismo, dispone de suficiente influencia para hallar los recursos necesarios y acelerar el proceso de toma de decisiones.

- Aceleración del avance por efecto de la sensación de urgencia

Es responsabilidad de la alta dirección, generar una sensación de urgencia y determinación con el fin de dotar a la iniciativa del ímpetu necesario para garantizar el avance permanente, sobre la base de la visión y los lineamientos del proyecto. La participación directa de la alta gerencia del proyecto y la constante comunicación del significado de la iniciativa de CRM son decisivas para el éxito del proyecto.

- Atractivo de la participación del proyecto Implica crear un eficaz ambiente de trabajo y tornar atractiva la participación del proyecto. Asimismo, debe comunicarse a los empleados involucrados los puestos que ocuparán en la organización una vez consumados los cambios. Su participación representa un aumento de su valor para la organización, tal como puede verse en el gráfico 4.

\section{Gráfico 4}

Perspectiva del compromiso de generar valor

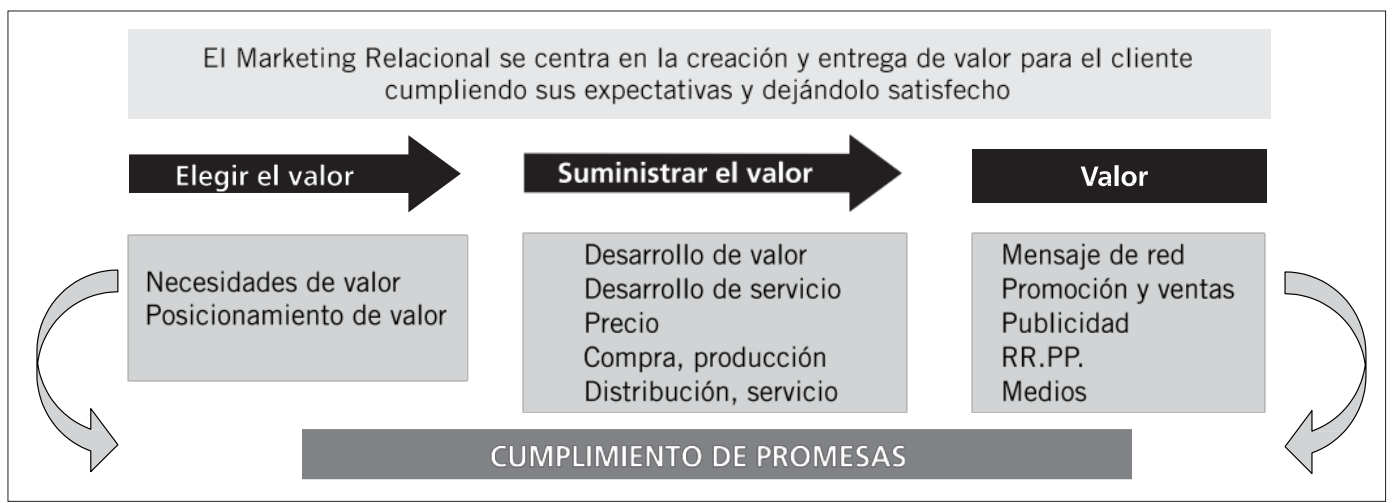

Fuente: Gronroos 1996: 144 
Propuesta de aplicación de la teoría CRM en las unidades productivas y comerciales del sector de confecciones...

- Permanente comunicación con las partes interesadas

Los empleados deben entender que la empresa ejecuta el proyecto para obtener beneficios de negocios, como lealtad, ventas cruzadas, mejor servicio al cliente, etcétera, y que todas las actividades persiguen la preservación de la competitividad de la organización, así como su capacidad para retener a los empleados competentes.

- La cabeza en su sitio (¡calma!) Indica no alentar en exceso las esperanzas. Es importante que la dirección controle las previsiones de los empleados y no cree falsas expectativas en torno al proyecto.

- Capacitación y educación Implica promover en el público objetivo la comprensión del CRM desde la perspectiva de negocios. Se debe explicar la estrategia general, la estrategia de clientes, las estrategias de canales y productos, el impacto de ello en el éxito y en el futuro de la organización, entre otros.

- Uso del diseño rápido de aplicaciones Se debe prestar atención a los requerimientos funcionales (cómo deberán usar el sistema los vendedores para consultar el estado de pedidos, créditos o pagos de facturas) y buscar una solución técnica razonable. En resumen, debe estimular la iniciativa, desarrollar el sentido de responsabilidad y apoyar el deseo de trabajar mejor.

- Rentabilidad de la implantación Implica la adquisición de hardware, software y programas de capacitación. Una implementación piloto, cuidadosamente seleccionada, será muy útil para ofrecer seguridad a quienes deberán tomar la decisión final de financiar la introducción del sistema en toda la organización.

- Prevención contra soluciones excesivamente especializadas

Los sistemas de CRM altamente personalizados pueden provocar dificultades particulares cuando se les actualiza con nuevas versiones de software. La documentación cuidadosa de la configuración y de los cambios en el código es un elemento vital de toda implantación de CRM y tecnología de información.
- Actitud crítica en la selección del método Proporciona la integración de la tecnología de información con los aspectos de negocios de una solución. Debe existir tanto una secuencia lógica de actividades del análisis a la implantación, como un marco temporal realista.

- Oleadas de implantación

La introducción del sistema se iniciará en cierto grupo o departamentos, y se debe disponer de tiempo para instalar el hardware. La empresa tiene que cerciorarse de que los empleados disponen de las habilidades necesarias de CRM y tecnología de información.

- Atención a las victorias rápidas

Implica mostrar algunas victorias rápidas a la organización, con el fin de convencer a los empleados de que vale la pena realizar un gran esfuerzo en el proyecto de CRM. Las victorias rápidas son argumentos convincentes de ventas en relación con un proyecto de CRM para las partes interesadas de la organización.

La gestión del marketing en la microempresa

La industria de la microempresa ha permitido el desarrollo económico y la modernización de muchos países por su capacidad de generar empleo, ingresos y divisas; así como, por su gran contribución a la descentralización.

Países como México, Italia, Argentina, Chile, Venezuela, Brasil, Uruguay, Colombia y Ecuador han encontrado en la microempresa un importante soporte para su desarrollo. Frente a las crisis que se presentan, el microempresario ha mostrado una capacidad de resistencia: sus tasas de crecimiento son superiores al promedio de otras industrias. Ello se debe a que en estos países se han desarrollado estrategias orientadas a impulsar el desarrollo de su potencial humano, lograr un mejor aprovechamiento de sus recursos naturales e impulsar el desarrollo tecnológico, integrando en este proceso diferentes sectores de la población. Esto se logra por medio de la articulación de empresas de diversas escalas y el fomento del desarrollo de la empresa de pequeña escala. 
Propuesta de aplicación de la teoría CRM en las unidades productivas y comerciales del sector de confecciones...

Esta situación ha dado lugar a:

- La diversificación de la oferta en el sector comercio, por el desarrollo de las actividades productivas de servicio o por la «puesta en valor» de nuevos atractivos comerciales.

- La ampliación progresiva de la demanda en el sector comercio, por el crecimiento masivo de servicios en el mundo.

- El crecimiento «agresivo» de la competitividad, dentro de un mercado extremadamente dinámico.

En este sentido, el estudio, los conocimientos y las aplicaciones del marketing son instrumentos indispensables en el sector comercio para orientar el examen de la demanda comercial y que esta sea potencial o efectiva. Asimismo, en el caso de la oferta comercial, para no adecuarla a las exigencias propias de la demanda sino para ofrecer nuevas y diversas propuestas, y posibilidades de selección.

Teniendo en cuenta lo dicho en el párrafo precedente, es absolutamente necesario, en el estudio y posterior aplicación de la teoría CRM, contar con el pleno conocimiento de los elementos e instrumentos de indagación, y de decisiones que entran en una «función de dirección». Esto no solamente por su absoluta y necesaria aplicación, sino porque el objetivo de dicha teoría es encontrar soluciones y alternativas, teniendo en cuenta que en este sector se encontrarán elementos «no controlables» que pueden condicionar la comercialización del producto y la excelencia en el servicio en la Plaza Gamarra.

Según Hayes (1995: 13), el marketing relacional es «el conjunto de actividades dirigidas hacia el establecimiento, desarrollo y mantenimiento de relaciones de intercambio exitosas».

En esta definición se han tenido presentes las particularidades y características del producto y servicio en la Plaza Gamarra. Esto es, la oferta y la demanda, elementos que requieren coordinación de las actividades empresariales para hacer el esfuerzo de acercar el producto y servicio al consumidor potencial.
Teniendo en cuenta los elementos de la anterior definición y agregando referencias sobre los niveles de decisión y técnicas de aplicación, Alcaide (2002: 47) define marketing relacional como «el proceso de identificar, establecer, mantener y acrecentar relaciones beneficiosas con los clientes y otros agentes implicados, y esto se realiza a través de la mutua entrega y cumplimiento de promesas». Este autor señala que el enfoque relacional se fundamenta en considerar cada transacción con los clientes como un simple eslabón de una gran cadena de transacciones, que deberá prolongarse durante un largo período.

Definición más coherente y completa en el sentido de que armoniza la totalidad de elementos que constituye el verdadero marketing relacional.

Beneficios del marketing relacional

La implantación del enfoque relacional aporta beneficios tanto a las empresas como a los clientes. Según Alcaide (2002), los beneficios que aporta el marketing relacional son los siguientes:

- Incremento de las compras.

- Costes operativos y de producción más bajos.

- Costes de marketing (vender a un nuevo cliente es más costoso que vender a un cliente actual) más bajos.

- Comunicación 'boca a boca' positiva.

- Eleva la percepción de valor y calidad total de los productos o servicios de las empresas.

- Consolida la lealtad de los clientes a la empresa, sus productos o servicios y marcas (retención, fidelización), lo que conduce a niveles de participación de mercado más altos y estables.

- Permite mantener altos y crecientes niveles de repetición de compra.

- Permite generar niveles de rentabilidad más altos en el mediano y largo plazo.

- Facilita el conocimiento a fondo de los clientes, lo que eleva las posibilidades de responder mejor a sus necesidades, deseos y expectativas $y$, en consecuencia, generar en ellos niveles de satisfacción más altos. 
Propuesta de aplicación de la teoría CRM en las unidades productivas y comerciales del sector de confecciones...

- El contacto directo permite obviar, reducir o neutralizar los problemas y obstáculos que, muchas veces, representan los intermediarios.

- Facilita la comprensión de los procesos de compra y toma de decisiones de los clientes.

- Permite centrar y orientar mejor las actividades del marketing tradicional.

\section{Desventajas del marketing relacional}

En relación con las desventajas de programas de CRM, Alet (1997) manifiesta que existen las siguientes:

- La implantación del CRM podría quedar limitada al departamento de informática, lo que implicaría que se vuelva irrelevante para la compañía y para el cliente que se intenta servir mejor.

- Poca participación del ápice estratégico de la organización y/o de los colaboradores.

- Inexistencia de un control en la información de nuestros clientes o no contar con una base de datos de los clientes actualizada.

- Costo proporcional elevado, por requerir asesoría del especialista, software especializado y capacitación del personal que deberá saber aplicarla de manera correcta.

- Proceso de evaluación lento y demorado.

- Uso inapropiado de las herramientas de fidelización eficaz.

Elementos estratégicos del marketing relacional

El servicio al cliente desempeña un papel básico en el inicio y mantenimiento de una relación empresa-cliente. Todo lo que engloba el concepto de servicio constituye una de las semillas más importantes para que las organizaciones puedan implantar una estrategia relacional en su mercado.

Bajo esta perspectiva, Alet (1997) establece cinco elementos estratégicos para el desarrollo del marketing relacional:

- Desarrollar un núcleo de servicio en torno al cual construir la relación con el cliente. Esto implica utilizar este elemento como arma estratégica y como aspecto diferenciador frente a la competencia. La hipótesis central de este planteamiento se fundamenta en que el cliente, ante ofertas muy semejantes, buscará aquellos proveedores que le ofrezcan mejores servicios.

- Individualizar la relación con el cliente. Es decir, la necesidad de una 'clientización' en las acciones realizadas por las empresas respecto de la prestación del servicio de manera continua.

- Aumentar el núcleo del servicio con beneficios extras. El cliente debe percibir que, frente al ofrecimiento de una serie de beneficios relacionales, recibe un valor adecuado por el mantenimiento de esta relación.

- Alentar la fidelización del cliente. Realización de esfuerzos permanentes para que el cliente se mantenga fiel a la empresa a lo largo del tiempo.

- Potenciar a los empleados de la organización para que la mejora de los resultados tenga repercusión en los clientes. Implica incrementar la oferta de los clientes, gracias a la rentabilidad que se obtiene de la relación.

\section{Metodología}

Las técnicas de recolección de datos es el análisis documental. En ese sentido, se utilizaron los archivos y registros disponibles en la División de Licencias de la Municipalidad de la Victoria, la Asociación de Centros Comerciales de Entretenimiento y Afines, el Ministerio de Industria, Turismo, Integración y Negociaciones Comerciales Internacionales (Mitinci).

Para la realización del presente estudio, se aplicó una encuesta cualitativa a los propietarios de los establecimientos ubicados en la Plaza Gamarra; así como a los clientes ${ }^{2}$. Además, se realizaron entrevistas en profundidad en el mismo emporio comercial, en el distrito de La Victoria.

2. En los anexos 1 y 2 se muestran las encuestas para los propietarios y clientes de la Plaza Gamarra. 
Propuesta de aplicación de la teoría CRM en las unidades productivas y comerciales del sector de confecciones...

La encuesta se realizó entre el 20 de noviembre de 2004 y el 20 de diciembre del mismo año, y tuvo una duración promedio de 10 minutos. En ese período, el encuestado procedió a marcar las respuestas y a absolver algunas consultas efectuadas por el encuestador.

Se eligió la técnica de la encuesta con preguntas cerradas, tipificada como dicotómicas, de elección múltiple, escala de Likert y escala de calificación, que permiten conocer las características que debe tener el servicio que ofrecerían los establecimientos de la Plaza Gamarra a sus clientes.

Las preguntas cerradas corresponden con el tipo de investigación porque son preguntas para medir actitudes, y así poder aplicar medidas estadísticas. Con relación a la población de visitantes y propietarios de las unidades productivas y comerciales, se utilizó el método probabilístico azar simple.

Se realizaron 30 preguntas a los propietarios de las unidades productivas y comerciales, las que se dividieron en tres ítems: estrategias de mercado, generalidades del servicio, centralismo del servicio y percepción.

Asimismo, se efectuaron 19 preguntas a los clientes del emporio de Gamarra, las cuales se dividieron en tres ítems: visita a Gamarra, servicios, modernidad y tecnología.

Para la reafirmación o negociación de las percepciones y satisfacciones de los clientes con respecto a los servicios en la Plaza Gamarra, se utilizaron instrumentos de recolección de la información: cuestionarios estructurados y guías de entrevistas.

Para el desarrollo de la investigación, se tuvo en cuenta a dos grupos:

- Primer grupo: propietarios de las unidades productivas y comerciales de la Plaza Gamarra, pues son generadores de empleo, fuentes de producción, de ingresos y promueven el desarrollo de un país.
- Segundo grupo: clientes de la Plaza Gamarra, cuya función consiste en tener un servicio personalizado, variedad de productos y servicios, y ser sujetos de la aplicación de herramientas de CRM.

A estos dos grupos se les administró los siguientes instrumentos:

- La ficha de registro de información en documentos.

- La guía de observación para el registro sistemático de las observaciones.

- Guía de entrevistas a los directivos de la Asociación de Comerciantes de la Plaza Gamarra, así como a expertos en CRM.

- Cuestionario aplicado a la muestra de los clientes de Gamarra y propietarios de las unidades productivas y comerciales.

La población de esta investigación se dividió en dos grupos:

- Visitantes al emporio comercial: 40.000 a 50.000 personas por día en el mes de julio de 2004 (Asociación de Centros Comerciales de Entretenimiento y Afines, 2003); y

- Número de establecimientos en la Plaza Gamarra: 5.901 (División de Registro de Licencias de la Municipalidad de la Victoria, 2003), de los cuales el $88 \%$ está conformado por el rubro de confecciones y venta de prendas de vestir, seguido por un 1,3\% de restaurantes, un $1,2 \%$ de fuentes de soda y un $9,5 \%$ de otros.

Es importante indicar que según estadísticas del Mitinci, en el año 2003, el distrito de La Victoria estuvo conformado en un $95 \%$ por microempresas, en un $4,7 \%$ por pequeñas empresas y en un $0,3 \%$ por grandes y medianas empresas.

En función de los dos grupos existentes, se estableció una muestra por cada uno de ellos, cuya suma será igual a la muestra total de la investigación.

Sobre la base de ello, la formulación de la población finita (Kinnear y Taylor 1993) para el primer grupo es la siguiente: 
Propuesta de aplicación de la teoría CRM en las unidades productivas y comerciales del sector de confecciones...

$$
n=\frac{4(p)(q) \cdot N}{e^{2}(N-1)+4 p \cdot q}
$$

Donde:

$\mathrm{n}=$ Muestra inicial

$\mathrm{N}=$ Población

pq = Campo de variabilidad del fenómeno por investigarse; $p$ representa los aciertos $(0,5)$ y $q$, los errores $(0,5)$.

e $=$ Nivel de precisión.

Reemplazando los datos tenemos:

$$
n=\frac{4(0,5)(0,5) \cdot 40.000}{(0,05)^{2}(40.000-1)+4(0,5)(0,5)}
$$

Donde: $\mathrm{n}=396$ cuestionarios

La muestra del segundo grupo será:

$$
n=\frac{4(p)(q) \cdot N}{e^{2}(N-1)+4 p \cdot q}
$$

Donde:

$\mathrm{N}=$ Población

pq = Campo de variabilidad del fenómeno por investigarse; $p$ representa los aciertos $(0,5)$ y q, los errores $(0,5)$.

e $=$ Nivel de precisión $(5 \%=0,05)$.

Reem iacalluu ius uaius telitıIus.

$$
\mathrm{n}=\frac{4(0,5)(0,5) \cdot 5.901}{(0,05)^{2}(5.901-1)+4(0,5)(0,5)}
$$

Donde: $\mathrm{n}=375$ cuestionarios

Presentación de resultados

- Propietarios de las unidades productivas y comerciales de la Plaza Gamarra

Pregunta 1: Usted ofrece sus servicios de acuerdo con las necesidades de los clientes

La pregunta estuvo dirigida a conocer la opinión de la muestra sobre los servicios que ofrecen los propietarios de las unidades productivas y comerciales de la Plaza Gamarra. Las respuestas muestran que el $73,3 \%$, una gran mayoría, a veces ofrece sus servicios en función de las necesidades del cliente. Sin embargo, cabe señalar que el $23,3 \%$ siempre lo realiza y tan solo un $2,7 \%$, nunca lo efectúa (véase el cuadro 1.

Cuadro 1

Usted ofrece sus servicios de acuerdo con las necesidades de los clientes

\begin{tabular}{|lcc|}
\hline & $\mathrm{N}^{\circ}$ encuestados & Porcentaje \\
\hline Nunca & 4 & $2,7 \%$ \\
A veces & 110 & $73,3 \%$ \\
Siempre & 35 & $23,3 \%$ \\
No respondieron & 1 & $0,7 \%$ \\
\hline TOTAL & 150 & $100,0 \%$ \\
\hline
\end{tabular}

Pregunta 2: ¿Hace uso de la publicidad/promoción para ofrecer sus productos?

Esta pregunta guarda relación directa con la anterior y los resultados muestran que un $50 \%$ usa publicidad/promoción para ofrecer sus productos; mientras que un $46 \%$ lo considera innecesario. Cabe señalar que este último es un porcentaje significativo (véase el cuadro 2).

Cuadro 2

¿Hace uso de la publicidad/promoción para ofrecer sus productos?

\begin{tabular}{|lcc|}
\hline & $N^{\circ}$ encuestados & Porcentaje \\
\hline Sí & 75 & $50,0 \%$ \\
No & 69 & $46,0 \%$ \\
No respondieron & 6 & $4,0 \%$ \\
\hline TOTAL & 150 & $100,0 \%$ \\
\hline
\end{tabular}

Si su respuesta es afirmativa, ¿por qué medios lo hace?

Las respuestas brindadas a la presente pregunta por parte de la muestra estudiada señalan que los propietarios realizan publicidad/promoción mediante volantes en un 53,6\%; seguido de un $38,1 \%$ que lo hace por radio. Sin embargo, el $4,1 \%$ y el $3,1 \%$ lo hacen por Internet y revistas/ periódicos, respectivamente (véase el cuadro 3). 
Propuesta de aplicación de la teoría CRM en las unidades productivas y comerciales del sector de confecciones...

Cuadro 3

¿Por qué medios lo hace?

\begin{tabular}{|lcc|}
\hline & $\mathrm{N}^{\circ}$ encuestados & Porcentaje \\
\hline TV & 1 & $1,0 \%$ \\
Radio & 37 & $38,1 \%$ \\
Volantes & 52 & $53,6 \%$ \\
Revistas / periódicos & 3 & $3,1 \%$ \\
Internet & 4 & $4,1 \%$ \\
\hline TOTAL & 97 & $100,0 \%$ \\
\hline
\end{tabular}

Pregunta 3: ¿Su oferta de servicios o productos se ha dirigido a nuevos segmentos de mercado? En la presente pregunta, se observa una tendencia de los propietarios de las unidades productivas y comerciales a no orientar su oferta de servicios o productos a nuevos segmentos de mercado: $71.3 \%$; en contraposición a un $28,3 \%$ que sí hace uso de nuevos segmentos de mercado (véase el cuadro 4).

\section{Cuadro 4}

¿Su oferta de servicios o productos se ha dirigido a nuevos segmentos de mercado?

\begin{tabular}{|lcc|}
\hline & $N^{\circ}$ encuestados & Porcentaje \\
\hline Sí & 43 & $28,7 \%$ \\
No & 107 & $71,3 \%$ \\
\hline TOTAL & 150 & $100,0 \%$ \\
\hline
\end{tabular}

Pregunta 4: ¿Ha creado nuevos productos y servicios para sus clientes a fin de aumentar las utilidades de su negocio?

La presente pregunta guarda directa relación con la creación de nuevos productos y servicios, y se puede observar que un $73 \%$ manifiesta hacerlo; mientras que un $26 \%$ no lo hace (véase el cuadro 5).

\section{Cuadro 5}

¿Ha creado nuevos productos y servicios para sus clientes a fin de aumentar las utilidades de su negocio?

\begin{tabular}{|lcr|}
\hline & $\mathrm{N}^{\circ}$ encuestados & Porcentaje \\
\hline Sí & 110 & $73,3 \%$ \\
No & 39 & $26,0 \%$ \\
No respondieron & 1 & $0,7 \%$ \\
\hline TOTAL & 150 & $100,0 \%$ \\
\hline
\end{tabular}

Pregunta 5: ¿Su empresa forma parte de un servicio integrado?

En el cuadro 6 se puede apreciar que en una mayoría de $75,3 \%$, la empresa no forma parte de los programas integrales del servicio. En cambio, un $20,7 \%$ sí lo hace.

Cuadro 6

¿Suempresa forma parte de un servicio integrado?

\begin{tabular}{|lcc|}
\hline & $\mathrm{N}^{\circ}$ encuestados & Porcentaje \\
\hline Sí & 31 & $20,7 \%$ \\
No & 113 & $75,3 \%$ \\
No respondieron & 6 & $4,0 \%$ \\
\hline TOTAL & 150 & $100,0 \%$ \\
\hline
\end{tabular}

Si su respuesta es afirmativa, el servicio integrado ofrece.

Esta pregunta guarda relación directa con la anterior, en tanto se refiere a definir qué tan apropiados son los servicios integrados. Se observa que un $44,4 \%$ manifiesta la importancia del conocimiento del producto, seguido de un $20,5 \%$ que opina acerca de la capacitación a sus vendedores (véase el cuadro 7).

Cuadro 7

El servicio integrado ofrece

\begin{tabular}{|c|c|c|}
\hline enc & $\begin{array}{l}\mathrm{N}^{\circ} \\
\text { estados }\end{array}$ & Porcentaje \\
\hline Rapidez de respuesta a las & & \\
\hline necesidades del cliente & 11 & $9,4 \%$ \\
\hline Cordialidad & 5 & $4,3 \%$ \\
\hline Conocimiento del producto & 52 & $44,4 \%$ \\
\hline Local apropiado & 4 & $3,4 \%$ \\
\hline Capacitación a sus vendedores & 24 & $20,5 \%$ \\
\hline Conocimiento del cliente & 11 & $9,4 \%$ \\
\hline Calidad en su servicio & 10 & $8,5 \%$ \\
\hline TOTAL & 117 & $100,0 \%$ \\
\hline
\end{tabular}

Pregunta 6: ¿Cómo califica la calidad de su servicio?

La respuesta de los propietarios de las unidades productivas y comerciales de la plaza Gamarra a esta pregunta fue la siguiente: un $81,3 \%$ considera que la calidad es buena; seguido de un $9,3 \%$ que manifiesta como muy buena y un $7,3 \%$, como regular (véase el cuadro 8). 
Propuesta de aplicación de la teoría CRM en las unidades productivas y comerciales del sector de confecciones...

Cuadro 8

Calidad del servicio

\begin{tabular}{|lcc|}
\hline & $\mathrm{N}^{\circ}$ encuestados & Porcentaje \\
\hline Muy mala & 1 & $0,7 \%$ \\
Mala & 0 & $0,0 \%$ \\
Regular & 11 & $7,3 \%$ \\
Buena & 122 & $81,3 \%$ \\
Muy buena & 14 & $9,3 \%$ \\
No respondieron & 2 & $1,3 \%$ \\
\hline TOTAL & 150 & $100,0 \%$ \\
\hline
\end{tabular}

Pregunta 7: ¿Cree que para lograr el desarrollo de las unidades productivas y comerciales de la Plaza Gamarra sea necesaria la participación de todos los sectores privados?

Las respuestas brindadas a la presente pregunta, por parte de la muestra estudiada, señalan que un $56,0 \%$ de los propietarios de las unidades productivas y comerciales considera necesaria la participación de todos los sectores privados; a diferencia de un $42,7 \%$, que manifiesta lo contrario (véase el cuadro 9).

\section{Cuadro 9}

¿Cree que para lograr el desarrollo de las unidades productivas y comerciales de la Plaza Gamarra sea necesaria la participación de todos los sectores privados?

\begin{tabular}{|lcc|}
\hline & $N^{\circ}$ encuestados & Porcentaje \\
\hline Sí & 84 & $56,0 \%$ \\
No & 64 & $42,7 \%$ \\
No respondieron & 2 & $1,3 \%$ \\
\hline TOTAL & 150 & $100,0 \%$ \\
\hline
\end{tabular}

Pregunta 8: Su empresa coordina con algún sector privado, ajeno a la actividad de su microempresa, para dar seguridad a sus clientes. Un $50,7 \%$ de la muestra estudiada manifiesta que su empresa coordina con algún sector privado, in- dependientemente de la actividad de su microempresa, para dar seguridad a sus clientes; sin embargo, un $48,0 \%$ no lo hace (véase el cuadro 10 ).

\section{Cuadro 10}

Su empresa coordina con algún sector privado, ajeno a la actividad de su microempresa, para dar seguridad a sus clientes

\begin{tabular}{|lcr|}
\hline & $\mathrm{N}^{\circ}$ encuestados & Porcentaje \\
\hline Sí & 76 & $50,7 \%$ \\
No & 72 & $48,0 \%$ \\
No respondieron & 2 & $1,3 \%$ \\
\hline TOTAL & 150 & $100,0 \%$ \\
\hline
\end{tabular}

Pregunta 9: Su empresa coordina con algún sector público, ajeno a la actividad de su microempresa, para dar seguridad a sus clientes.

En el caso de la coordinación con algún sector público, independientemente de a la actividad de su microempresa, para dar seguridad a sus clientes, los encuestados contestaron en un $65,3 \%$ que sí es necesario. Sin embargo, un $26 \%$ opina lo contrario (véase el cuadro 11).

Cuadro 11

Su empresa coordina con algún sector público, ajeno a la actividad de su microempresa, para dar seguridad a sus clientes

\begin{tabular}{|lcc|}
\hline & $N^{\circ}$ encuestados & Porcentaje \\
\hline Sí & 39 & $26,0 \%$ \\
No & 98 & $65,3 \%$ \\
No respondieron & 13 & $8,7 \%$ \\
\hline TOTAL & 150 & $100,0 \%$
\end{tabular}

Si su respuesta es afirmativa, indique de qué modo. Un 55,9\% manifestó su preocupación por mejorar la infraestructura física y de comunicaciones; seguido de un $39,8 \%$, que opinó que mediante la educación a los comerciantes se logrará mayor atención al cliente (véase el cuadro 12).

Cuadro 12

Si su respuesta es afirmativa, indique de qué modo

\begin{tabular}{|lrr|}
\hline & $N^{\circ}$ encuestados & Porcentaje \\
\hline Coordinando acciones de seguridad y protección & 1 & $1,1 \%$ \\
Educando a los comerciantes para mayor atención al cliente & 37 & $39,8 \%$ \\
Mejorando infraestructura física y de comunicaciones & 52 & $55,9 \%$ \\
Contratando personal de vigilancia & 3 & $3,2 \%$ \\
\hline TOTAL & 93 & $100,0 \%$ \\
\hline
\end{tabular}


Propuesta de aplicación de la teoría CRM en las unidades productivas y comerciales del sector de confecciones...

Pregunta 10: ¿Realiza usted consulta a profesionales especializados en comercialización para mejorar la calidad del servicio que ofrece?

Las respuestas señalan que un $52,0 \%$ de los encuestados nunca ha consultado a profesionales especializados para recibir asesoría en comercialización y así mejorar la calidad del servicio; mientras que un $45,3 \%$ a veces lo ha hecho (véase el cuadro 13).

\section{Cuadro 13}

¿Realiza usted consulta a profesionales especializados en comercialización para mejorar la calidad del servicio que ofrece?

\begin{tabular}{|lcc|}
\hline & $\mathrm{N}^{\circ}$ encuestados & Porcentaje \\
\hline Nunca & 78 & $52,0 \%$ \\
A veces & 68 & $45,3 \%$ \\
Siempre & 4 & $2,7 \%$ \\
\hline TOTAL & 150 & $100,0 \%$ \\
\hline
\end{tabular}

Pregunta 11: ¿Forma parte de asociaciones con microempresas del mismo rubro a fin de mejorar el servicio o producto?

En el siguiente cuadro se puede resaltar que un $73,3 \%$ de la muestra estudiada manifiestan que forman parte de asociaciones de microempresarios, frente a un $20 \%$ que opina lo contrario (véase el cuadro 14).

\section{Cuadro 14}

¿Forma parte de asociaciones con microempresas del mismo rubro a fin de mejorar el servicio o producto?

\begin{tabular}{|lcc|}
\hline & $N^{\circ}$ encuestados & Porcentaje \\
\hline Sí & 110 & $73,3 \%$ \\
No & 39 & $26,0 \%$ \\
No respondieron & 1 & $0,7 \%$ \\
\hline TOTAL & 150 & $100,0 \%$ \\
\hline
\end{tabular}

Pregunta 12: ¿Sus productos o servicios son iguales a la de su competencia?

En el cuadro 15 se aprecia que un 72,7\% manifiesta que sus productos o servicios son iguales a los de su competencia.
Cuadro 15

Sus productos o servicios son iguales a la de su competencia

\begin{tabular}{|lcc|}
\hline & $N^{\circ}$ encuestados & Porcentaje \\
\hline Sí & 109 & $72,7 \%$ \\
No & 40 & $26,7 \%$ \\
No respondieron & 1 & $0,7 \%$ \\
\hline TOTAL & 150 & $100,0 \%$ \\
\hline
\end{tabular}

Pregunta 13: Si su respuesta es afirmativa, ¿brinda productos o servicios complementarios al servicio o producto que usted ofrece?

En el siguiente cuadro se puede observar que solo un $49,7 \%$ de los encuestados muestra iniciativas para brindar productos o servicios complementarios; en comparación con un 47,3\%, que no lo demuestra (véase el cuadro 16).

Cuadro 16

¿Brinda productos o servicios complementarios al servicio o producto que usted ofrece?

\begin{tabular}{|lcc|}
\hline & $N^{\circ}$ encuestados & Porcentaje \\
\hline Sí & 79 & $49,7 \%$ \\
No & 71 & $47,3 \%$ \\
\hline TOTAL & 150 & $100,0 \%$ \\
\hline
\end{tabular}

Pregunta 14: Si su respuesta es afirmativa, exprese de qué manera

Al respecto, el 52,5\% de la muestra opinó que los descuentos promueven la oferta de servicios complementarios, seguido de un $23,7 \%$ que está a favor de las promociones y un $18,6 \%$ que prefiere los remates (véase el cuadro 17).

Cuadro 17

Si su respuesta es afirmativa, exprese de qué manera

\begin{tabular}{|lcr|}
\hline & $N^{\circ}$ encuestados & Porcentaje \\
\hline Promociones & 14 & $23,7 \%$ \\
Descuentos & 31 & $52,5 \%$ \\
Sorteos & 3 & $5,1 \%$ \\
Remates & 11 & $18,6 \%$ \\
\hline TOTAL & 59 & $100,0 \%$ \\
\hline
\end{tabular}


Propuesta de aplicación de la teoría CRM en las unidades productivas y comerciales del sector de confecciones...

Pregunta 15: Considera Ud. que los servicios que brinda la Plaza Gamarra son

Los resultados obtenidos en la presente pregunta nos permite destacar que un $68,5 \%$ considera buenos los servicios que se ofrecen en la Plaza Gamarra, un 29,5\% manifiesta que son regulares y tan solo el $2 \%$ los consideran excelentes (véase el cuadro 18).

\section{Cuadro 18}

Considera Ud. que los servicios que brinda la Plaza Gamarra son

\begin{tabular}{|lrc|}
\hline & $\mathrm{N}^{\circ}$ encuestados & Porcentaje \\
\hline Malos & 0 & $0,0 \%$ \\
Regulares & 44 & $29,5 \%$ \\
Buenos & 102 & $68,5 \%$ \\
Excelentes & 3 & $2,0 \%$ \\
No respondieron & 1 & $0,7 \%$ \\
\hline TOTAL & 149 & $100,0 \%$ \\
\hline
\end{tabular}

Pregunta 16: Considera usted que el emporio comercial de Gamarra establezca convenio con empresas de taxis para brindar servicios de transporte a la plaza Gamarra

Al respecto, el $96,7 \%$ de la muestra considera importante que la Plaza Gamarra establezca convenios con empresas de taxis para brindar un mejor servicio de transporte, frente a un 3,3\% que considera lo contrario (véase el cuadro 19).

\section{Cuadro 19}

Considera usted que el emporio comercial de Gamarra establezca convenio con empresas de taxis para brindar servicios de transporte a la Plaza Gamarra

\begin{tabular}{|lcc|}
\hline & $N^{\circ}$ encuestados & Porcentaje \\
\hline Sí & 145 & $96,7 \%$ \\
No & 5 & $3,3 \%$ \\
\hline TOTAL & 150 & $100,0 \%$ \\
\hline
\end{tabular}

Pregunta 17: ¿ConsideraUd. que se debe efectivizar este servicio en la Plaza Gamarra? En términos de efectivizar el servicio, un porcentaje mayoritario $(96,7 \%)$ lo considera prioritario; mientras que un reducido porcentaje $(2,7 \%)$ opina lo contrario (véase el cuadro 20).
Cuadro 20

¿Considera Ud. que se debe efectivizar este servicio en la Plaza Gamarra?

\begin{tabular}{|lcc|}
\hline & $N^{\circ}$ encuestados & Porcentaje \\
\hline Sí & 145 & $96,7 \%$ \\
No & 4 & $2,7 \%$ \\
No respondieron & 1 & $0,7 \%$ \\
\hline TOTAL & 150 & $100,0 \%$ \\
\hline
\end{tabular}

Pregunta 18: ¿Está de acuerdo que debe brindarse un servicio de transporte a los clientes de la Plaza Gamarra desde puntos estratégicos de Lima Metropolitana?

Si bien un $72 \%$ consideró importante incrementar este servicio, un $28 \%$ opinó lo contrario (véase el cuadro 21).

Cuadro 21

¿Está de acuerdo que debe brindarse un servicio de transporte a los clientes de la Plaza Gamarra desde puntos estratégicos de Lima Metropolitana?

\begin{tabular}{|lcc|}
\hline & $N^{\circ}$ encuestados & Porcentaje \\
\hline Sí & 108 & $72,0 \%$ \\
No & 42 & $28,0 \%$ \\
\hline TOTAL & 150 & $100,0 \%$ \\
\hline
\end{tabular}

Pregunta 19: ¿Cree usted que el nivel de servicios que ofrece Gamarra satisface las necesidades de los clientes?

Los resultados obtenidos en la presente pregunta nos muestran que la mayoría (94\%) considera que el nivel de servicio brindado satisface las necesidades del cliente. En cambio, un porcentaje no significativo $(5,3 \%)$ opina lo contrario (véase el cuadro 22).

Cuadro 22

¿Cree usted que el nivel de servicios que ofrece Gamarra satisface las necesidades de los clientes?

\begin{tabular}{|lrr|} 
& $N^{\circ}$ encuestados & Porcentaje \\
\hline Sí & 141 & $94,0 \%$ \\
No & 8 & $5,3 \%$ \\
No respondieron & 1 & $0,7 \%$ \\
\hline TOTAL & 150 & $100,0 \%$ \\
\hline
\end{tabular}


Propuesta de aplicación de la teoría CRM en las unidades productivas y comerciales del sector de confecciones...

Si la respuesta es positiva, ¿cuál es el nivel que usted considera?

En la misma pregunta se hizo referencia al nivel de servicio ofrecido en la plaza Gamarra, encontrándose que un $56,7 \%$ consideró el nivel medio; seguido de un $37,6 \%$ que manifestó el alto y tan solo un $5 \%$ lo consideró muy alto (véase el cuadro 23 ).

Cuadro 23

Si la respuesta es positiva, ¿cuál es el nivel que usted considera?

\begin{tabular}{|lcc|}
\hline & $\mathrm{N}^{\circ}$ encuestados & Porcentaje \\
\hline Muy alto & 7 & $5,0 \%$ \\
Alto & 53 & $37,6 \%$ \\
Medio & 80 & $56,7 \%$ \\
Bajo & 0 & $0,0 \%$ \\
Muy bajo & 1 & $0,7 \%$ \\
\hline TOTAL & 141 & $100,0 \%$ \\
\hline
\end{tabular}

Pregunta 20: ¿Considera que la Plaza Gamarra es un emporio comercial carente de modernidad y bajo nivel tecnológico?

En el presente caso, debe destacarse que un 83,3\% ha señalado que sí es un emporio comercial carente de modernidad y tecnología. Sin embargo, un $16,7 \%$ opina lo contrario (véase el cuadro 24 ).

Cuadro 24

¿Considera que la Plaza Gamarra es un emporio comercial carente de modernidad y bajo nivel tecnológico?

\begin{tabular}{|lcc|}
\hline & $N^{\circ}$ encuestados & Porcentaje \\
\hline Sí & 125 & $83,3 \%$ \\
No & 25 & $16,7 \%$ \\
\hline TOTAL & 150 & $100,0 \%$ \\
\hline
\end{tabular}

Pregunta 21: ¿Qué mejoras como empresario espera ofrecer en la Plaza Gamarra?

A pesar de que la pregunta tiene una connotación subjetiva, un 22,2\% consideró la higiene del lugar y la rapidez en el servicio; seguido de un $19,6 \%$ que señaló la calidad en los servicios. Es importante destacar que el 15\% opinó que ofrecería un mejor trato personal en los establecimientos; el $14,7 \%$, un mejor servicio de información y señalización; y el 12,3\%, la seguridad y protección frente a los posibles robos (véase el cuadro 25).

Pregunta 22: El personal que trabaja en su establecimiento se siente involucrado en el servicio que ofrece

En el cuadro 26 se puede apreciar que el $94,7 \%$ sí se siente involucrado; mientras que el $4 \%$ opina lo contrario.

Cuadro 26

El personal que trabaja en su establecimiento se siente involucrado en el servicio que ofrece

\begin{tabular}{|lcc|}
\hline & $\mathrm{N}^{\circ}$ encuestados & Porcentaje \\
\hline Sí & 142 & $94,7 \%$ \\
No & 6 & $4,0 \%$ \\
No respondieron & 2 & $1,3 \%$ \\
\hline TOTAL & 150 & $100,0 \%$ \\
\hline
\end{tabular}

Pregunta 23: El trato que su personal de su establecimiento brinda a sus clientes es

En el cuadro 27 debe destacarse que un $76,7 \%$ del personal que trabaja en las unidades productivas y comerciales de la plaza Gamarra, consideró como bueno el servicio que brinda a sus clientes; seguido de un $16 \%$ que lo calificó como muy bueno; y un $6 \%$, como regular.

Cuadro 25

¿Qué mejoras como empresario espera ofrecer en la Plaza Gamarra?

\begin{tabular}{|lcc|}
\hline & $N^{\circ}$ encuestados & Porcentaje \\
\hline Mejores precios & 38 & $7,5 \%$ \\
Calidad en los servicios & 99 & $19,6 \%$ \\
Seguridad y protección a los posibles robos & 62 & $12,3 \%$ \\
Higiene del lugar y rapidez en el servicio & 112 & $22,2 \%$ \\
Mejor trato personal en los establecimientos & 76 & $15,0 \%$ \\
Mayor número de servicios & 44 & $8,7 \%$ \\
Mejor servicio de información y señalización & 74 & $14,7 \%$ \\
Mayor formalización de los establecimientos comerciales & 50 & $9,9 \%$ \\
\hline TOTAL & 505 & $100,0 \%$ \\
\hline
\end{tabular}


Propuesta de aplicación de la teoría CRM en las unidades productivas y comerciales del sector de confecciones...

Cuadro 27

El trato que su personal de su establecimiento brinda a sus clientes es

\begin{tabular}{|lcc|}
\hline & $N^{\circ}$ encuestados & Porcentaje \\
\hline Muy malo & 0 & $0,0 \%$ \\
Malo & 2 & $1,3 \%$ \\
Regular & 9 & $6,0 \%$ \\
Bueno & 115 & $76,7 \%$ \\
Muy bueno & 24 & $16,0 \%$ \\
\hline TOTAL & 150 & $100,0 \%$ \\
\hline
\end{tabular}

Pregunta 24: ¿Cómo considera la labor de la comisaría de la Victoria, a fin de mejorar las condiciones de seguridad en la Plaza Gamarra?

El $63,3 \%$ de los encuestados la considera regular; el $19.3 \%$, buena y el $14,7 \%$, mala (véase el cuadro 28).

Cuadro 28

¿Cómo considera la labor de la comisaría de la Victoria, a fin de mejorar las condiciones de seguridad en la Plaza Gamarra?

\begin{tabular}{|lcc|}
\hline & $N^{\circ}$ encuestados & Porcentaje \\
\hline Muy buena & 0 & $0,0 \%$ \\
Buena & 29 & $19,3 \%$ \\
Regular & 95 & $63,3 \%$ \\
Mala & 22 & $14,7 \%$ \\
Muy mala & 2 & $1,3 \%$ \\
No respondieron & 2 & $1,3 \%$ \\
\hline TOTAL & 150 & $100,0 \%$
\end{tabular}

Pregunta 25: ¿Considera Ud. que es necesario mayor formalización de los establecimientos comerciales para optimizar la gestión de las unidades productivas y comerciales de Gamarra?

Al respecto, un porcentaje significativo de la muestra $(81,3 \%)$ no estuvo de acuerdo con el hecho de formalizar los establecimientos comerciales, tal como se puede apreciar en el cuadro 29

\section{Cuadro 29}

¿Considera Ud. que es necesario mayor formalización de los establecimientos comerciales para optimizar la gestión de las unidades productivas y comerciales de Gamarra?

\begin{tabular}{|lrr|}
\hline & $N^{\circ}$ encuestados & Porcentaje \\
\hline Muy de acuerdo & 1 & $0,7 \%$ \\
De acuerdo & 0 & $0,0 \%$ \\
No de acuerdo ni en desacuerdo & 11 & $7,3 \%$ \\
En desacuerdo & 122 & $81,3 \%$ \\
Muy en desacuerdo & 14 & $9,3 \%$ \\
No respondieron & 2 & $1,3 \%$ \\
\hline TOTAL & 150 & $100,0 \%$ \\
\hline
\end{tabular}

Pregunta 26: ¿Considera que debe ampliarse la cantidad de servicios de información en la Plaza Gamarra?

Los resultados obtenidos en la presente pregunta nos muestran que una mayoría significativa $(99,3 \%)$ opinó que debe difundirse la cantidad de servicios de información en la Plaza Gamarra (véase el cuadro 30).

Cuadro 30

¿Considera que debe ampliarse la cantidad de servicios de información en la Plaza Gamarra?

\begin{tabular}{|lcc|}
\hline & $\mathrm{N}^{\circ}$ encuestados & Porcentaje \\
\hline Sí & 149 & $99,3 \%$ \\
No & 1 & $0,7 \%$ \\
\hline TOTAL & 150 & $100,0 \%$ \\
\hline
\end{tabular}

Pregunta 27: ¿Considera que debe ampliarse la cantidad de señalizaciones en los establecimientos de Gamarra?

El 99,3\% de los encuestados manifestó su interés en ampliar la cantidad de señalizaciones en la Plaza Gamarra; en tanto que el 0,7\%, opinó lo contrario (véase el cuadro 31).

Cuadro 31

¿Considera que debe ampliarse la cantidad de señalizaciones en los establecimientos de Gamarra?

\begin{tabular}{|lcc|}
\hline & $N^{\circ}$ encuestados & Porcentaje \\
\hline Sí & 149 & $99,3 \%$ \\
No & 1 & $0,7 \%$ \\
\hline TOTAL & 150 & $100.0 \%$ \\
\hline
\end{tabular}

Pregunta 28: ¿Sabía Ud. que la instalación de campañas de telemarketing es necesaria en Gamarra para tener acceso a los productos con mayor ventaja? El 57,3\% de los encuestados dio como respuesta que sí tenían conocimiento de ello; mientras que el $42 \%$, no lo consideraba necesario (véase el cuadro 32).

Cuadro 32

¿Sabía Ud. que la instalación de campañas de telemarketing es necesaria en Gamarra para tener acceso a los productos con mayor ventaja?

\begin{tabular}{|lcc|}
\hline & $\mathrm{N}^{\circ}$ encuestados & Porcentaje \\
\hline Sí & 86 & $57,3 \%$ \\
No & 63 & $42,0 \%$ \\
No respondieron & 1 & $0,7 \%$ \\
\hline TOTAL & 150 & $100.0 \%$ \\
\hline
\end{tabular}


Propuesta de aplicación de la teoría CRM en las unidades productivas y comerciales del sector de confecciones...

Pregunta 29: ¿Considera Ud. que el diseño de canales virtuales (comunicación electrónica, conferencias) incrementaría el interés para obtener mayor información actualizada y personalizada de Gamarra?

Esta pregunta guarda relación directa con la anterior, en tanto está referida a definir el interés de obtener mayor información actualizada y personalizada mediante diseños de canales virtuales (comunicación electrónica, conferencias). Tal como se puede apreciar en el cuadro 33, el 92\% manifestó su interés y un $8 \%$ opinó lo contrario.

\section{Cuadro 33}

Considera Ud. que el diseño de canales virtuales (comunicación electrónica, conferencias) incrementaría el interés para obtener mayor información actualizada y personalizada de Gamarra?

\begin{tabular}{|lcc|}
\hline & $N^{\circ}$ encuestados & Porcentaje \\
\hline Sí & 138 & $92,0 \%$ \\
No & 12 & $8,0 \%$ \\
\hline TOTAL & 150 & $100.0 \%$ \\
\hline
\end{tabular}

Pregunta 30: ¿Considera Ud. importante la implementación de la tecnología para determinar volúmenes de compra de los clientes y factores causantes de la deserción e historial de consumo para tomar mejores decisiones y realizar acciones pertinentes de fidelización?

Al respecto, un significativo $96 \%$ muestra su interés en la aplicación de la tecnología; mientras que un $3,3 \%$ no lo considera necesario (véase el cuadro 34).

\section{Cuadro 34}

¿Considera Ud. importante la implementación de la tecnología para determinar volúmenes de compra de los clientes y factores causantes de la deserción e historial de consumo para tomar mejores decisiones y realizar acciones pertinentes de fidelización?

\begin{tabular}{|lcc|}
\hline & $N^{\circ}$ encuestados & Porcentaje \\
\hline Sí & 144 & $96,0 \%$ \\
No & 5 & $3,3 \%$ \\
No respondieron & 1 & $0,7 \%$ \\
\hline TOTAL & 150 & $100,0 \%$ \\
\hline
\end{tabular}

\section{- Clientes de la Plaza Gamarra}

Pregunta 1: Durante su visita en la Plaza Gamarra, ¿qué lugares visitó?

La pregunta estuvo dirigida a saber la opinión de la muestra en cuanto a los lugares que visitó durante su estadía en la Plaza Gamarra, observándose que el 64,2\% visitó lugares de confección y prendas de vestir. Cabe señalar que el $18,8 \%$ visitó restaurantes y fuentes de soda, tal como puede apreciarse en el cuadro 35 o gráfico 39.

Cuadro 35

Durante su visita en la Plaza Gamarra, ¿qué lugares visitó?

\begin{tabular}{|lcc|}
\hline \multicolumn{1}{|c}{ Frecuencia } & Porcentaje \\
\hline $\begin{array}{l}\text { a. Lugares de confecciones } \\
\text { y ventas de prendas de } \\
\text { vestir }\end{array}$ & 147 & $64,2 \%$ \\
$\begin{array}{l}\text { b. Lugares como restaurantes } \\
\text { y fuentes de soda }\end{array}$ & 43 & $18,8 \%$ \\
$\begin{array}{l}\text { c. Lugares como tragamonedas, } \\
\text { discotecas }\end{array}$ & 4 & $1,7 \%$ \\
$\begin{array}{l}\text { d. Lugares como boticas y } \\
\text { farmacias }\end{array}$ & 9 & $3,9 \%$ \\
$\begin{array}{l}\text { e. Lugares como ferreterías, } \\
\text { pinturas y plásticos }\end{array}$ & 8 & $3,5 \%$ \\
$\begin{array}{l}\text { f. Lugares como oficinas } \\
\text { administrativas, } \\
\text { consultorios médicos }\end{array}$ & 1 & $0,4 \%$ \\
$\begin{array}{l}\text { g. Lugares como bancos y } \\
\text { librerías }\end{array}$ & 17 & $7,4 \%$ \\
\hline TOTAL & 229 & $100,0 \%$ \\
\hline
\end{tabular}

Pregunta 2: Si ya estuvo en la Plaza Gamarra, ¿su estadía fue?

Esta pregunta se refiere a qué tan satisfecha o insatisfecha fue su permanencia en la Plaza Gamarra. En ese sentido, se observa que el 55,3\% calificó como satisfecha su estadía en la Plaza Gamarra; mientras que para el $35,5 \%$, esta fue 'ni satisfecha ni insatisfecha' (véase el cuadro 36). 
Propuesta de aplicación de la teoría CRM en las unidades productivas y comerciales del sector de confecciones...

Cuadro 36

Si ya estuvo en la Plaza Gamarra, ¿su estadía fue?

\begin{tabular}{|lrr|}
\hline & Frecuencia & Porcentaje \\
\hline - Totalmente satisfecha & 8 & $5,3 \%$ \\
- Satisfecha & 84 & $55,3 \%$ \\
- Ni satisfecha ni & & \\
insatisfecha & 54 & $35,5 \%$ \\
- Insatisfecha & 5 & $3,3 \%$ \\
- Totalmente insatisfecha & 1 & $0,7 \%$ \\
\hline TOTAL & 152 & $100,0 \%$ \\
\hline
\end{tabular}

Pregunta 3: ¿Que le ofrece la Plaza Gamarra? Esta pregunta guarda directa relación con los productos y/o servicios que ofrece la Plaza Gamarra. Los resultados muestran que para el $42,1 \%$ son los precios bajos y para el $39,50 \%$, la variedad de productos (véase el cuadro 37). Estas respuestas corroboran los resultados de la primera pregunta.

Cuadro 37

¿Que le ofrece la Plaza Gamarra?

\begin{tabular}{|lrc|}
\hline & Frecuencia & Porcentaje \\
\hline - Precios bajos & 114 & $42,1 \%$ \\
- Productos de calidad & 37 & $13,7 \%$ \\
- Variedad en los & & \\
$\quad \begin{array}{l}\text { productos } \\
\text { - Lugares de }\end{array}$ & 107 & $39,5 \%$ \\
$\quad$ entretenimiento & 5 & $1,8 \%$ \\
- Totalmente insatisfecha & 8 & $3,0 \%$ \\
\hline TOTAL & 271 & $100,0 \%$ \\
\hline
\end{tabular}

Pregunta 4: ¿Con qué frecuencia visita Ud. el emporio comercial de Gamarra?

Una mayoría relativa de los clientes $(32,7 \%)$ tiende a visitar el emporio comercial de Gamarra cada 2 a 6 meses, seguido del $20 \%$, cuya frecuencia de visita es de una vez al mes. Cabe mencionar que el $19,3 \%$ de los clientes no especificó la frecuencia de su visita (véase el cuadro 38 ).
Cuadro 38

¿Con qué frecuencia visita Ud. el emporio comercial de Gamarra?

\begin{tabular}{|lcc|}
\hline & Frecuencia & Porcentaje \\
\hline - Diario & 1 & $0,7 \%$ \\
- Ínterdiario & 0 & $0,0 \%$ \\
- Una vez por semana & 6 & $4,0 \%$ \\
- Dos veces por semana & 2 & $1,3 \%$ \\
- Cada 10 días & 0 & $0,0 \%$ \\
- Cada 15 días & 13 & $8,7 \%$ \\
- Cada 20 días & 2 & $1,3 \%$ \\
- Una vez al mes & 30 & $20,0 \%$ \\
- De 2 a 6 meses & 49 & $32,7 \%$ \\
- De 6 a 12 meses & 18 & $12,0 \%$ \\
- No especifica & 29 & $19,3 \%$ \\
\hline TOTAL & 150 & $100,0 \%$ \\
\hline
\end{tabular}

Pregunta 5: Desde su última visita a la Plaza Gamarra, ¿considera que los servicios han mejorado?

Como se puede apreciar en el cuadro 39), para la mayoría de los clientes, los servicios recibidos en la Plaza Gamarra han mejorado (73,3\%); a diferencia de un $24 \%$, que piensa lo contrario y un $2,7 \%$, que prefirió no opinar.

Cuadro 39

Desde su última visita a la Plaza Gamarra, ¿considera que los servicios han mejorado?

\begin{tabular}{|lcc|}
\hline & Frecuencia & Porcentaje \\
\hline - Sí & 110 & $73,3 \%$ \\
- No & 36 & $24,0 \%$ \\
- No responde & 4 & $2,7 \%$ \\
\hline TOTAL & 150 & $100,0 \%$ \\
\hline
\end{tabular}


Propuesta de aplicación de la teoría CRM en las unidades productivas y comerciales del sector de confecciones...

Pregunta 6: ¿Tiene intención de regresar a la plaza Gamarra?

Ante esta pregunta, el $42,1 \%$ de los encuestados contestó que definitivamente sí regresaría al emporio (véase el cuadro 40), lo cual guarda correspondencia con el porcentaje que manifestó que posiblemente regresaría a la Plaza Gamarra.

Cuadro 40

¿Tiene intención de regresar a la plaza Gamarra?

\begin{tabular}{|lcr|}
\hline & Frecuencia & Porcentaje \\
\hline $\begin{array}{l}\text { - Definitivamente si } \\
\text { regresaría }\end{array}$ & 64 & $42,1 \%$ \\
$-\begin{array}{l}\text { Posiblemente si } \\
\text { regresaría }\end{array}$ & 64 & $42,1 \%$ \\
- Probablemente no & & $3,3 \%$ \\
$\begin{array}{l}\text { regresaría } \\
\text { - Definitivamente no } \\
\text { regresaría }\end{array}$ & 5 & $0.0 \%$ \\
- No podría regresar & 19 & $12,5 \%$ \\
\hline TOTAL & 152 & $100,0 \%$ \\
\hline
\end{tabular}

Pregunta 7: ¿En qué momento del día prefiere visitar la Plaza Gamarra?

En el cuadro 41 se puede observar que el $42,7 \%$ de la muestra estudiada acude al emporio comercial de Gamarra durante la mañana. Sin embargo, es relevante que igual porcentaje lo visita en la tarde.

Cuadro 41

¿Enqué momento del día prefiere visitar la Plaza Gamarra?

\begin{tabular}{|lrr|}
\hline & Número & Porcentaje \\
\hline - Mañana & 64 & $42,7 \%$ \\
- Tarde & 64 & $42,7 \%$ \\
- Noche & 5 & $3,3 \%$ \\
- No responde & 17 & $11,3 \%$ \\
\hline TOTAL & 150 & $100,0 \%$ \\
\hline
\end{tabular}

Pregunta 8: ¿Tiempo que permaneció en la Plaza Gamarra?

Un mayoría relativa (68\%) dio como respuesta que permaneció en el emporio entre 2 y 3 horas; seguida de un $22,7 \%$ que mencionó que permaneció por más de 4 horas (véase el cuadro 42).
Cuadro 42

¿Tiempo que permaneció en la Plaza Gamarra?

\begin{tabular}{|lcc|}
\hline & Número & Porcentaje \\
\hline A. 1 hora & 14 & $9,3 \%$ \\
B. 2 horas & 49 & $32,7 \%$ \\
C. 3 horas & 53 & $35,3 \%$ \\
D. + de 4 horas & 34 & $22,7 \%$ \\
\hline TOTAL & 150 & $100,0 \%$ \\
\hline
\end{tabular}

Si fuera la alternativa $A$ o $B$, ¿cuál de las siguientes razones limitaron su estadía en la Plaza Gamarra?

Las personas encuestadas, en un 27,3\%, consideraron como la razón fundamental: los robos y secuestros; un $25,6 \%$ contestó que fue el hecho de no tener más dinero; y un $24,8 \%$, el poco transporte seguro (véase el cuadro 43).

Cuadro 43

Si fuera la alternativa A o B, ¿cuál de las siguientes razones limitaron su estadía en la Plaza Gamarra?

\begin{tabular}{|lrr|}
\hline \multicolumn{1}{|c}{ Cantidad } & Porcentaje \\
\hline - No tener más dinero en efectivo & 31 & $25,6 \%$ \\
- Poco transporte público seguro & 30 & $24,8 \%$ \\
- No tuve mayor información & 19 & $15,7 \%$ \\
acerca de otros productosy & & \\
servicios que ofrece la Plaza & & \\
Gamarra & & \\
- Lejanía del hogar & 8 & $6,6 \%$ \\
- Robos / secuestros & 33 & $27,3 \%$ \\
\hline TOTAL & 121 & $100,0 \%$ \\
\hline
\end{tabular}

Pregunta 9: ¿Cuál fue el nivel de expectativa de su visita a la Plaza Gamarra de los siguientes servicios?

Con relación a los servicios que se ofrece, se observa un nivel de expectativa regular en todos los lugares visitados por parte de los clientes de Gamarra: lugares de confección y prendas de vestir (45\%); restaurantes y fuentes de soda $(62,4 \%)$; tragamonedas y discotecas $(41,3 \%)$; boticas y farmacias $(48,8 \%)$; ferreterías, pinturas y plásti$\cos (45,1 \%)$; oficinas administrativas, consultorios médicos (38,2\%); bancos y librerías $(51,7 \%)$; tal como se observa en el cuadro 44. 
Propuesta de aplicación de la teoría CRM en las unidades productivas y comerciales del sector de confecciones...

Cuadro 44

¿Cuál fue el nivel de expectativa de su visita a la Plaza Gamarra de los siguientes servicios?

\begin{tabular}{|c|c|c|c|c|c|}
\hline & \multicolumn{2}{|c|}{ Cantidad } & \multicolumn{2}{|c|}{ Porcentaje } \\
\hline & & Subtotal & Total & Subtotal & Total \\
\hline $\begin{array}{l}\text { Lugares de confecciones y } \\
\text { prendas de vestir }\end{array}$ & $\begin{array}{l}\text { Muy bajo } \\
\text { Bajo } \\
\text { Regular } \\
\text { Alto } \\
\text { Muy alto }\end{array}$ & $\begin{array}{r}2 \\
5 \\
67 \\
66 \\
9\end{array}$ & 149 & $\begin{array}{r}1,3 \% \\
3,4 \% \\
45,0 \% \\
44,3 \% \\
6,0 \%\end{array}$ & $100,0 \%$ \\
\hline $\begin{array}{l}\text { Lugares como restaurantes y } \\
\text { fuentes de soda }\end{array}$ & $\begin{array}{l}\text { Muy bajo } \\
\text { Bajo } \\
\text { Regular } \\
\text { Alto } \\
\text { Muy alto }\end{array}$ & $\begin{array}{r}13 \\
23 \\
68 \\
4 \\
1\end{array}$ & 109 & $\begin{array}{r}11,9 \% \\
21,1 \% \\
62,4 \% \\
3,7 \% \\
0,9 \%\end{array}$ & $100,0 \%$ \\
\hline $\begin{array}{l}\text { Lugares como tragamonedas, } \\
\text { discotecas }\end{array}$ & $\begin{array}{l}\text { Muy bajo } \\
\text { Bajo } \\
\text { Regular } \\
\text { Alto } \\
\text { Muy alto }\end{array}$ & $\begin{array}{r}25 \\
16 \\
33 \\
4 \\
2\end{array}$ & 80 & $\begin{array}{r}31,3 \% \\
20,0 \% \\
41,3 \% \\
5,0 \% \\
2,5 \%\end{array}$ & $100,0 \%$ \\
\hline $\begin{array}{l}\text { Lugares como boticas y } \\
\text { farmacias }\end{array}$ & $\begin{array}{l}\text { Muy bajo } \\
\text { Bajo } \\
\text { Regular } \\
\text { Alto } \\
\text { Muy alto }\end{array}$ & $\begin{array}{r}18 \\
17 \\
41 \\
8 \\
0\end{array}$ & 84 & $\begin{array}{r}21,4 \% \\
20,2 \% \\
48,8 \% \\
9,5 \% \\
0,0 \%\end{array}$ & $100,0 \%$ \\
\hline $\begin{array}{l}\text { Lugares como ferreterías, } \\
\text { pinturas y plásticos }\end{array}$ & $\begin{array}{l}\text { Muy bajo } \\
\text { Bajo } \\
\text { Regular } \\
\text { Alto } \\
\text { Muy alto }\end{array}$ & $\begin{array}{r}16 \\
24 \\
37 \\
4 \\
1\end{array}$ & 82 & $\begin{array}{r}19,5 \% \\
29,3 \% \\
45,1 \% \\
4,9 \% \\
1,2 \%\end{array}$ & $100,0 \%$ \\
\hline $\begin{array}{l}\text { Lugares como oficinas } \\
\text { administrativas, consultorios } \\
\text { médicos }\end{array}$ & $\begin{array}{l}\text { Muy bajo } \\
\text { Bajo } \\
\text { Regular } \\
\text { Alto } \\
\text { Muy alto }\end{array}$ & $\begin{array}{r}22 \\
23 \\
29 \\
2 \\
0\end{array}$ & 76 & $\begin{array}{r}28,9 \% \\
30,3 \% \\
38,2 \% \\
2,6 \% \\
0,0 \%\end{array}$ & $100,0 \%$ \\
\hline $\begin{array}{l}\text { Lugares como bancos y } \\
\text { librerías }\end{array}$ & $\begin{array}{l}\text { Muy bajo } \\
\text { Bajo } \\
\text { Regular } \\
\text { Alto } \\
\text { Muy alto }\end{array}$ & $\begin{array}{r}12 \\
21 \\
46 \\
9 \\
1\end{array}$ & 89 & $\begin{array}{r}13,5 \% \\
23,6 \% \\
51,7 \% \\
10,1 \% \\
1,1 \%\end{array}$ & $100,0 \%$ \\
\hline
\end{tabular}

Pregunta 10: Realizar compras en la Plaza Gamarra

La pregunta guarda relación con la recomendación del cliente respecto de comprar en el emporio. Los resultados muestran que un significativo $74 \%$ lo recomendaría con reserva; mientras que un $21,3 \%$ lo recomendaría enfáticamente (véase el cuadro 45).

\section{Cuadro 45}

Realizar compras en la Plaza Gamarra

\begin{tabular}{|lrr|}
\hline & Número & Porcentaje \\
\hline - No lo recomendaría & 4 & $2,7 \%$ \\
- Lo recomendaría con reserva & 111 & $74,0 \%$ \\
- Lo recomendaría enfáticamente & 32 & $21,3 \%$ \\
- No contestaron & 3 & $2,0 \%$ \\
\hline TOTAL & 150 & $100,0 \%$ \\
\hline
\end{tabular}


Propuesta de aplicación de la teoría CRM en las unidades productivas y comerciales del sector de confecciones...

Pregunta 11: ¿Cuál es el volumen de compras que usted realiza en la Plaza Gamarra?

Esta pregunta implica conocer la cantidad de dinero que gasta el cliente en Gamarra. Las respuestas muestran que para un $59,3 \%$ de los encuestados, el volumen de compra que le sirve para satisfacer sus necesidades se ubica entre S/ . 100 a S/. 500; seguido de un 17,3\%, para quienes dicho volumen corresponde a S/. 500 - S/. 1.000 , lo que representa mayor capacidad adquisitiva (véase el cuadro 46).

\section{Cuadro 46}

¿Cuál es el volumen de compras que usted realiza en la Plaza Gamarra?

\begin{tabular}{|lcr|}
\hline & Cantidad & Porcentaje \\
\hline - De S/. 5.00 a Sl. 100 & 28 & $18,7 \%$ \\
- De S/. 100 a SI. 500 & 89 & $59,3 \%$ \\
- De S/. 500 a Sl. 1.000 & 26 & $17,3 \%$ \\
- De S/. 1.000 a S/. 1.500 & 7 & $4,7 \%$ \\
- Más de S/. 1.500 & 0 & $0,0 \%$ \\
\hline TOTAL & 150 & $100,0 \%$ \\
\hline
\end{tabular}

Pregunta 12: ¿Está satisfecho con la calidad del servicio que brinda en la Plaza Gamarra?

Los resultados obtenidos nos permiten detectar que el $50,7 \%$ se encuentra satisfecho (véase el cuadro 47).; sin embargo, el 39,3\% es indiferente (ni satisfecho ni insatisfecho).

\section{Cuadro 47}

¿Está satisfecho con la calidad del servicio que brinda en la Plaza Gamarra?

\begin{tabular}{|lcc|}
\hline & Cantidad & Porcentaje \\
\hline - Totalmente insatisfecho & 2 & $1,3 \%$ \\
- Insatisfecho & 8 & $5,3 \%$ \\
- Ni insatisfecho, ni satisfecho & 59 & $39,3 \%$ \\
- Satisfecho & 76 & $50,7 \%$ \\
- Totalmente satisfecho & 5 & $3,3 \%$ \\
\hline TOTAL & 150 & $100,0 \%$ \\
\hline
\end{tabular}

Pregunta 13: ¿Recibe información sobre los servicios que ofrece la Plaza Gamarra?

En el cuadro 48 se puede apreciar que un $92 \%$ de los clientes, una mayoría relativa, no recibe ninguna información del emporio comercial de Gamarra. Este es un dato preocupante, pues está relacionado con las actitudes que ponen en práctica los clientes durante su visita a Gamarra.
Cuadro 48

¿Recibe información sobre los servicios que ofrece la Plaza Gamarra?

\begin{tabular}{|lrr|}
\hline & Cantidad & Porcentaje \\
\hline - Sí & 11 & $7,3 \%$ \\
- No & 138 & $92,0 \%$ \\
- No responde & 1 & $0,7 \%$ \\
\hline TOTAL & 150 & $100,0 \%$ \\
\hline
\end{tabular}

Si su respuesta es afirmativa, ¿en qué medios publicitarios lo recibe?

En el cuadro 49 se puede observar que el grado de conocimiento es por medios publicitarios, lo que supone un nivel de motivación. Así, se tiene que el 38,5\% escucha publicidad de la Plaza Gamarra por radio; el 30,8\% la recibe por los medios escritos (periódico) y el $23,1 \%$, por folletos.

Cuadro 49

Si su respuesta es afirmativa, ¿en qué medios publicitarios lo recibe?

\begin{tabular}{|lcc|}
\hline & Cantidad & Porcentaje \\
\hline - Internet & 0 & $0,0 \%$ \\
- Radio & 5 & $38,5 \%$ \\
- Folletos & 3 & $23,1 \%$ \\
- Periódicos & 4 & $30,8 \%$ \\
- Instituciones como & 1 & $7,7 \%$ \\
$\quad$ Prompyme, Apemipem & & \\
etcétera & & \\
\hline TOTAL & 13 & $100,0 \%$ \\
\hline
\end{tabular}

Pregunta 14: ¿Sabe usted que cuenta con los servicios de apoyo permanente de serenazgos y PNP?

En el cuadro 50 se muestra que el $55,3 \%$ de clientes no tenía conocimiento de las acciones de seguridad establecidas en la Plaza Gamarra; mientras que el $44,7 \%$ manifestó recibir información al respecto.

Cuadro 50

¿Sabe usted que cuenta con los servicios de apoyo permanente de serenazgos y PNP?

\begin{tabular}{|lcc|} 
& Cantidad & Porcentaje \\
\hline - Sí & 67 & $44,7 \%$ \\
- No & 83 & $55,3 \%$ \\
\hline TOTAL & 150 & $100,0 \%$ \\
\hline
\end{tabular}


Propuesta de aplicación de la teoría CRM en las unidades productivas y comerciales del sector de confecciones...

Pregunta 15: ¿Considera que la Plaza Gamarra es un emporio comercial carente de modernidad y bajo nivel tecnológico?

En el presente caso, cabe destacar que un 57,3\% consideró que es un emporio comercial que no se ha modernizado y no aplica herramientas de fidelización; mientras que en un $42 \%$ señaló lo contrario (véase el cuadro 51).

Cuadro 51

¿Considera que la Plaza Gamarra es un emporio comercial carente de modernidad y bajo nivel tecnológico?

\begin{tabular}{|lcr|}
\hline & Cantidad & Porcentaje \\
\hline - Sí & 86 & $57,3 \%$ \\
- No & 63 & $42,0 \%$ \\
- No responde & 1 & $0,7 \%$ \\
\hline TOTAL & 150 & $100,0 \%$ \\
\hline
\end{tabular}

Pregunta 16: ¿Considera usted que la innovación tecnológica son necesarias en Gamarra?

Se debe mencionar que, de manera significativa, el $96 \%$ de los clientes manifestó que considera necesaria la aplicación de herramientas tecnológicas para mejorar la eficiencia en el servicio en Gamarra (véase el cuadro 52).

\section{Cuadro 52}

¿Considera usted que la innovación tecnológica son necesarias en Gamarra?

\begin{tabular}{|lrr|}
\hline & Cantidad & Porcentaje \\
\hline - Sí & 144 & $96,0 \%$ \\
- No & 5 & $3,3 \%$ \\
- No responde & 1 & $0,7 \%$ \\
\hline TOTAL & 150 & $100,0 \%$ \\
\hline
\end{tabular}

Pregunta 17: ¿Sabía usted que la instalación de campañas de telemarketing es necesaria en Gamarra para tener acceso a productos de mayor ventaja?

Tal como se muestra en el cuadro 53, una mayoría significativa (82\%) dio como respuesta que es necesario aplicar campañas de telemarketing con la finalidad de estar permanentemente informado acerca de las novedades que ofrece el emporio comercial de Gamarra.
Cuadro 53

¿Sabía usted que la instalación de campañas de telemarketing es necesaria en Gamarra para tener acceso a productos de mayor ventaja?

\begin{tabular}{|lcc|}
\hline & Cantidad & Porcentaje \\
\hline - Sí & 123 & $82,0 \%$ \\
- No & 26 & $17,3 \%$ \\
- No responde & 1 & $0,7 \%$ \\
\hline TOTAL & 150 & $100,0 \%$ \\
\hline
\end{tabular}

Pregunta 18: ¿Considera usted que el diseño de canales virtuales (comunicación electrónica, conferencias) incrementaría el interés para obtener mayor información actualizada y personalizada en Gamarra?

Esta pregunta guarda relación directa con la anterior, pues se trata de definir qué tan práctico y útil puede ser el diseño de canales virtuales. Las respuestas muestran que un significativo $95,3 \%$ consideró oportuna la aplicación de estos diseños virtuales para incrementar la eficiencia del emporio de Gamarra (véase cuadro 54).

\section{Cuadro 54}

¿Considera usted que el diseño de canales virtuales (comunicación electrónica, conferencias) incrementaría el interés para obtener mayor información actualizada y personalizada en Gamarra?

\begin{tabular}{|lcc|}
\hline & Cantidad & Porcentaje \\
\hline - Sí & 143 & $95,3 \%$ \\
- No & 7 & $4,7 \%$ \\
\hline TOTAL & 150 & $100,0 \%$ \\
\hline
\end{tabular}

Pregunta 19: ¿Considera usted importante la implementación de la tecnología para determinar volúmenes de compra de los clientes y factores causantes de la deserción e historial de consumo para tomar mejores decisiones y realizar acciones pertinentes de fidelización?

Tal como se muestra en el cuadro 55, un porcentaje significativo de la muestra (98\%) así lo manifiesta.

\section{Cuadro 55}

¿Considera usted importante la implementación de la tecnología para determinar volúmenes de compra de los clientes y factores causantes de la 
Propuesta de aplicación de la teoría CRM en las unidades productivas y comerciales del sector de confecciones...

deserción e historial de consumo para tomar mejores decisiones y realizar acciones pertinentes de fidelización?

\begin{tabular}{|lrr|}
\hline & Cantidad & Porcentaje \\
\hline - Sí & 147 & $98,0 \%$ \\
- No & 1 & $0,7 \%$ \\
- No responde & 2 & $1,3 \%$ \\
\hline TOTAL & 150 & $100,0 \%$ \\
\hline
\end{tabular}

\section{Conclusiones:}

Con respecto a los propietarios de las unidades productivas y comerciales de la Plaza Gamarra

En el presente estudio se puede apreciar que las unidades productivas y comerciales están ofreciendo sus servicios sin tener en cuenta las necesidades del cliente. Los resultados muestran que solamente un $73,3 \%$ (110 propietarios) se ubica en la categoría de 'A veces'; mientras que 23,3\%, en la categoría de 'Siempre'. Esta situación nos estaría indicando que una minoría de dichos propietarios no cuenta con los conocimientos necesarios para realizar una óptima gestión de calidad del servicio, sustentada en el marketing relacional, ya que no han seguido cursos especializados en la aplicación de las estrategias de fidelización de clientes.

Asimismo, este hecho confirma lo sustentado por Lehu (2001), que la aplicación de la teoría CRM se propone mejorar el desempeño actual en el trabajo que realiza el personal. Para ello, sostiene que tiene varios métodos, dentro del cual se encuentra el método de capacitación en el trabajo. Este método incluye la rotación de puestos, en el cual el empleado desempeña una serie de actividades laborales durante un periodo determinado, que contribuye a capacitar al trabajador en diversas áreas. Otro método considerado es la inducción, que consiste en verificar si el empleado tiene las condiciones específicas para ejecutar una labor predeterminada, según los interesas de la empresa. Finalmente, se tiene el método de aprendizaje, por medio del cual un especialista en el área capacita al empleado en la teoría de CRM y el marketing de servicios.
En este aspecto, los propietarios de las unidades productivas y comerciales del emporio de Gamarra, así como el Presidente de la Asociación de Comerciantes de Gamarra y otros ejecutivos vinculados a entidades de las micro y pequeñas empresas, han dado testimonio mediante las entrevistas que, efectivamente, uno de los problemas más agudos es el déficit de programas integrales de servicio para satisfacer las necesidades y exceder las expectativas de los clientes.

Asimismo, estas precisiones son corroboradas con los planteamientos teóricos de Horovitz (1996). Dicho autor señala que el área de actividades de aplicación de técnicas de personal integra procesos destinados a determinar las necesidades humanas de la organización y obtener el personal necesario para la organización, mantenerlo y desarrollarlo permanentemente. Cabe señalar que los empleados trabajan en equipo.

En ese mismo derrotero, todo parece indicar que las estrategias de CRM deben ser aplicadas en su verdadera dimensión y, sobre todo, en el nivel ejecutivo y operativo del emporio comercial de Gamarra, en vista de que no ejecutan planes estratégicos en la gestión de marketing de servicios y fidelización de clientes. Así, teniendo en consideración la problemática de su jurisdicción, podrían elevar dichas propuestas a la alta gerencia del emporio.

Este estudio también nos permite establecer que deben ampliarse la cantidad de servicios en la Plaza Gamarra, considerando la innovación y la permanente identificación de las necesidades y deseos de los clientes. Esto constituye un avance en la gestión organizacional, pues al generar valor agregado fortalece su proceso de transformación.

Los entrevistados expertos en CRM sostuvieron que el personal que presta servicios en la plaza Gamarra no reúne los requisitos de preparación y profesionalización, pues la selección no se realiza en función de sus habilidades y cualidades. Ellos sugieren efectuar una evaluación y calificación previa al personal que es asigna- 
Propuesta de aplicación de la teoría CRM en las unidades productivas y comerciales del sector de confecciones...

do para prestar servicios en dicho emporio comercial.

En vista de dichos resultados, se recurrió a los valiosos aportes realizados por Gonzales (2003) quien señala que la selección de personal es una función básica para obtener personal con condiciones óptimas para permitir su mejor desempeño laboral competitivo. De la misma forma, Cabal (2003) sostiene con acierto que el administrador realiza la selección de personal teniendo en cuenta que los postulantes al cargo cuentan con los requisitos de competencia profesional para el cargo.

Estas precisiones se corroboran con los planteamientos teóricos de Brown (2001), quien menciona que la mayor parte de las compañías competitivas atraviesan actualmente el proceso de definición de la visión, los procesos y las tecnologías que necesitan para centrarse en el cliente. La eficiencia y eficacia, cada vez mayor de esas organizaciones, en un mercado caracterizado por la enorme multiplicidad de canales y una poderosa tecnología emergente, tienen grandes implicaciones para todas las compañías; y por qué no en el emporio de Gamarra.

\section{Con relación a los clientes de la Plaza Gamarra}

Los clientes del emporio de Gamarra han dado testimonio, mediante sus declaraciones, que efectivamente uno de los problemas más agudos es la carencia de modernidad, seguridad, formalidad y bajo nivel tecnológico.

Lo anteriormente descrito confirma los resultados obtenidos por Gonzales (2003) quien manifiesta que es importante la intervención del Gobierno en la implementación de medidas que lleven al mejoramiento de la situación económica, política y social del país -en especial, en la capacitación sostenible en el tiempo-, que faciliten el potencial como foco de desarrollo al brindar condiciones objetivas para atraer inversiones nuevas, expandir a nuevos mercados y generar valor agregado.

Es necesario señalar que un 95,3\% (143) de los clientes considera oportuna la aplicación de ca- nales virtuales (comunicación electrónica, conferencias) para obtener mayor información actualizada y personalizada en Gamarra

Estas precisiones permiten arribar a conclusiones previas, en las cuales los grandes cambios y desafíos del CRM obligan a que las organizaciones enfrenten este mundo altamente cambiante y globalizado. Es necesario el desarrollo de su capacidad para conocer, prever y administrar las necesidades de sus clientes reales y potenciales mediante el adecuado despliegue de personal calificado en el trato al cliente, procesos óptimos y tecnologías facilitadoras.

Por otro lado, existe la necesidad de que el emporio comercial de Gamarra desarrolle indicadores como el Customer Life Time Value (CLTV), el cual mide la rentabilidad del cliente durante su permanencia en la Plaza Gamarra y modelos predictivos de deserción como Predective Churn, los cuales analizan la información del cliente, factores causantes de deserción e historial de consumo.

En cuanto a la arquitectura tecnológica de CRM, esta debe ser integrada por el CRM interactivo, que administra y gestiona los diferentes canales de interacción con el cliente (Contact Center).

Un segundo elemento es el CRM operativo, responsable de la gestión, los procesos de negocio, orientados a las transacciones de servicio o ventas; así como, a la administración de la base de clientes.

El CRM analítico, como tercer componente, implementa el datawarehouse corporativo, cuya información será analizada para permitir el grado de conocimiento del cliente, involucrando el modelo de segmentación de CLTV y los modelos predictivos de deserción (Predective Churn).

Finalmente, en el tema de una moderna concepción de administración de marketing, no debemos olvidar lo sustentado por Hayes (1995) respecto de la capacitación del personal. Esta debe estar vinculada al aspecto de la capacitación per- 
Propuesta de aplicación de la teoría CRM en las unidades productivas y comerciales del sector de confecciones...

manente, que permite estar en condiciones de realizar un manejo tecnológico adecuado realmente operativo, que posibilita dominar una situación y encarar algún problema.

\section{- Aplicación}

En un inicio, se busca conocer con mayor detalle a los clientes e identificar aquellos a quienes se debe brindar la excelencia en el servicio para lograr su fidelización. La lealtad de los clientes se puede definir como un comportamiento repetitivo de compra de los productos o servicios de la empresa. El motivo por el cual el cliente repite la compra no se basa principalmente en el precio, sino en una actitud favorable del cliente hacia la empresa.

La lealtad supone ventajas para la empresa, como la exclusividad del cliente, la venta cruzada y la publicidad barata, pues los clientes leales suelen convertirse en promotores no pagados. Lograr lealtad en los clientes es un proceso evolutivo y gradual, en la medida que la empresa incremente el nivel de relaciones y pasa por las siguientes etapas:

\section{a) Adquisición}

En esta etapa, que está destinada a conocer al cliente, la lealtad es muy débil, pues no se basa en relaciones sino en percepciones de producto y precio. En la actualidad, la Plaza Gamarra se encuentra en esta etapa. Sin embargo, su modelo de adquisición tendrá que adaptarse a una estrategia de CRM tomando en cuenta los siguientes factores:

- La segmentación de clientes, que permite a la empresa un eficiente direccionamiento de su oferta comercial, se debe basar principalmente en las necesidades del cliente. Esto no desecha los criterios de segmentación demográficos, geográficos o conductuales; sino que da prioridad al conocimiento del cliente. El emporio comercial de Gamarra debe llevar a cabo investigaciones de mercado orientados a conocer las necesidades de los clientes antes de lanzar una oferta comercial.
- Las campañas de ventas deben complemen- tarse con campañas de adquisición de da- tos del cliente. Es decir, luego de que un prospecto se convirtió en cliente de Gamarra, por lo menos, debe haber una pri- mera interacción con el cliente para darle la bienvenida (por ejemplo, Welcome call). En esta interacción se debe capturar la información del cliente que no fue captada en el momento de la venta, la cual será útil en las siguientes etapas de la estrategia.

b) Retención

Esta etapa se orienta a maximizar la relación con el cliente, con el fin de incrementar sus niveles de satisfacción.

- Inicialmente se deben facilitar las interacciones con el cliente, para poder obtener más información de él. En ese sentido, se debe implementar el Contact Center, el cual consta de una serie de medios por los cuales se brinda un servicio permanente, de manera personalizada y rápida a los clientes; que incorpora el uso de Internet para crear nuevos modelos de comunicación, junto con servicios de correo electrónico, chat, conferencias web, etcétera. Estos nuevos canales posibilitan al cliente el acceso a información y funciones de autoservicio, con independencia de la forma de contacto que establezca con Gamarra, manteniendo en todo momento un entorno amigable y una misma visión de la empresa.

Entre las funciones que debe cumplir el Contact Center se tienen:

- Resolver dudas o problemáticas referentes a algún servicio ofrecido, trámite por realizar o reclamos de los clientes.

- Proveer información acerca de los productos y servicios ofrecidos.

- Ejecutar las campañas de telemarketing (nuevas promociones o programas de retención).

- Tomar las llamadas y monitorear los progresos de las requisiciones de los clientes y los problemas. 
Propuesta de aplicación de la teoría CRM en las unidades productivas y comerciales del sector de confecciones...

Sobre la base de la información capturada en las interacciones, el siguiente paso consiste en la diferenciación de los clientes, que se realizará en función del perfilamiento, según las características que se han identificado, pero también según su valor. Esta es la primera aproximación en la determinación del valor del cliente y se basa principalmente en el volumen de ingreso que representa para Gamarra.

- La Asociación de Comerciantes de Gamarra debe promover y facilitar las interacciones de los clientes mediante:

- Retroalimentación de los clientes, por medio de un buzón de quejas o sugerencias, las que se deberán analizar y constituirse en fuente de mejora continua.

- Aplicación de encuestas de satisfacción, que pueden ser personales o vía telefónica.

- Seguimiento de servicio a los clientes; es decir, se realizarán llamadas de verificación de manera periódica, para asegurarse que los clientes hayan sido atendidos correctamente.

- En el caso de clientes empresariales, visitas periódicas de los propietarios de las unidades comerciales con el fin de conocer sus necesidades actuales y expectativas del servicio.

- En cada interacción, la intención principal gira en torno a responder a las inquietudes del cliente. Sin embargo, se debe aprovechar esta oportunidad para demostrar que la Plaza Gamarra lo identifica claramente con un cliente, ratificando la información que anteriormente se ha captado de él e incluso captando más información. Además, en lo posible, se deben aplicar las estrategias de venta cruzada.

- En la primera instancia, el emporio comercial de Gamarra debe ser capaz de reaccionar rápidamente ante una deserción. En estos casos, el emporio deberá interactuar de manera reactiva.

\section{c) Fidelización}

En esta etapa se establecen relaciones de largo plazo con los clientes que son rentables para la Plaza Gamarra. Las interacciones en esta etapa son más largas y personalizadas. La fidelización del cliente, en primera instancia, implica personalizar la relación con él. Este es el paso por el cual se generan claramente los beneficios hacia el cliente y logramos su confianza para que se mantenga leal.

- No es posible que las unidades productivas y comerciales de la Plaza Gamarra otorguen un trato personalizado a todos sus clientes, razón por la cual deberá, por medio del soporte tecnológico, brindar un nivel de servicio básico a ciertos clientes y un nivel óptimo a sus mejores clientes (heavy users).

- Otro componente necesario para conseguir la fidelización de los clientes es la adopción de modelos predictivos de deserción. Estos modelos analizan la información del cliente (demografía, geografía, aficiones, etcétera), los factores causantes de la deserción (precio, servicio al cliente, servicio básico, etc.) y su historial de consumo, para pronosticar un posible desgaste en la preferencia de estos.

- Los posibles clientes vulnerables son tomados en cuenta en las campañas de lealtad, de retención o de ventas ascendentes/cruzadas. Este tipo de técnicas aseguran una respuesta proactiva a la Plaza Gamarra y minimiza los efectos de las deserciones.

Por último, se recomienda aplicar tecnología informática que involucre a todas aquellas áreas de la agremiación de comerciantes de Gamarra que constituyan un punto de contacto con el cliente, como son:

- Servicio al cliente, incluye el soporte a los canales de comunicación y servicio, permite al emporio comercial de Gamarra manejar las consultas, los problemas o asuntos de los clientes 
Propuesta de aplicación de la teoría CRM en las unidades productivas y comerciales del sector de confecciones...

de forma efectiva y eficiente. Al mismo tiempo, facilita la venta cruzada o ascendente.

- Ventas, debe proporcionar a la fuerza de ventas el acceso a la información crítica de clientes y a las herramientas que mejoran su habilidad para vender efectivamente, como también la de administrar su tiempo. Por ejemplo: administración de contactos y funciones de calendario.

- Marketing, debe proporcionar herramientas para administrar campañas promocionales, generar iniciativas de telemarketing y desarrollar los modelos analíticos de segmentación y predicción.

\section{Referencias}

ALCAIDE C., J. C.

2002 Alta fidelidad: técnicas e ideas operativas para lograr la lealtad del cliente a través del servicio. Madrid: Esic editorial.

ALET, J.

1997 Marketing relacional. Barcelona: Ediciones 2000.

BERRY, L.

1993 Relationships Marketing. México: Prentice Hall.

BROWN, S.

2001 Administración de las relaciones con los clientes. México, D.F.: Oxford University Press.

CABAL, M.

2003 Evolución de las micro empresas y pequeñas empresas en Latinoamérica. Santo Domingo: Fondomicro.

\section{GONZÁLES, J.}

2003 Redes de la informalidad en Gamarra. Lima: Editorial Universitaria.

GRONROOS, C.

1996 «Relationship Marketing: Strategic and Tactical Implications». En: Management Decisions, vol. 34, $\mathrm{N}^{\circ} 3$, pp. 5-14.
HAYES, B.

1995 Cómo medir la satisfacción del cliente. Segunda edición. Barcelona: Ediciones Gestión 2000.

HOROVITZ, J.

1996 La calidad del servicio. Primera edición. Madrid: McGraw Hill.

KINNEAR, T. y J. TAYLOR

1993 Investigación de mercados: un enfoque aplicado. $4^{a}$ edición. Bogotá, Colombia: McGrawHill.

KOTLER, P.

1995 Administración de Marketing. $4^{a}$ edición. Sao Paulo: Atlas.

LEHU, J. M.

2001 Fidelizar al cliente. Ediciones Paidós Ibérica S.A.

PAYNE, A.

1996 La esencia de la mercadotecnia de servicios. Madrid: Editorial Prentice Hall.

SWIFT, R. S.

2002 CRM, Cómo mejorar las relaciones con los clientes. Editorial Prentice Hall. 
Propuesta de aplicación de la teoría CRM en las unidades productivas y comerciales del sector de confecciones...

\section{Anexo 1}

Encuesta para las unidades productivas y comerciales de la Plaza Gamarra

La encuesta aplicada para determinar las características del servicio y estrategias de mercadeo de las unidades productivas y comerciales de la Plaza Gamarra, tuvo como objetivo fundamental:

1 Recoger la información de su quehacer profesional para conocer las limitaciones de sus servicios, productos y problemas de gestión;

2 Proponer medidas y alternativas para mejorar la eficiencia empresarial.

\section{ÁREA: ESTRATEGIAS DE MERCADO}

1. Usted ofrece sus servicios de acuerdo a las necesidades de los clientes
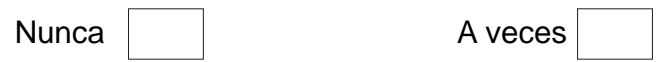

Siempre

2. ¿Hace uso de la publicidad / promoción para ofrecer sus servicios?

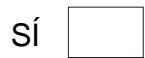

NO

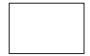

Si su respuesta es afirmativa, ¿Por qué medios lo hace?

- TV

- Radio

- Volantes

- Revistas / periódicos

- Internet

3. ¿Su oferta de servicios o productos se han dirigido a nuevos segmentos de mercado?

sí

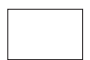

NO

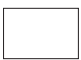

4. ¿Ha creado nuevos productos y servicios para sus clientes a fin de aumentar las utilidades de su negocio?

Sí

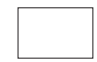

NO

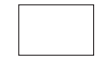

5. ¿Su empresa forma parte de un servicio integrado?
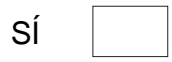

NO

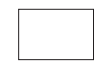

Si su respuesta es afirmativa, el servicio integrado ofrece:

- Rapidez de respuesta a las necesidades del cliente

- Cordialidad

- Conocimiento del producto

- Local apropiado

- Capacitación a sus vendedores

- Conocimiento del cliente

- Calidad en el servicio

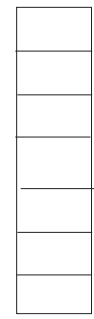


Propuesta de aplicación de la teoría CRM en las unidades productivas y comerciales del sector de confecciones...

6. ¿Cómo califica la calidad de su servicio?

- Muy mala

- Mala

- Regular

- Buena

- Muy buena

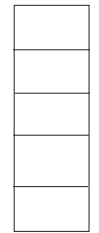

7. ¿Cree que para lograr el desarrollo de las unidades productivas y comerciales de la Plaza Gamarra sea necesario la participación de todos los sectores privados?

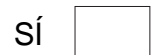

NO

8. ¿Su empresa coordina con algún sector privado, ajeno a la actividad de su microempresa, para dar seguridad a sus clientes?

Sí

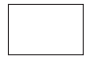

NO

9. ¿Su empresa coordina con algún sector público, ajeno a la actividad de su microempresa, para dar seguridad a sus clientes?

sí

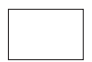

NO

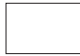

Si su respuesta es afirmativa, indique de qué modo:

- Coordinando acciones de seguridad y protección.

- Educando a los comerciantes para mayor atención al cliente

- Mejorando infraestructura física y de comunicaciones.

- Contratando personal de vigilancia

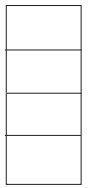

10. Realiza usted consulta a profesionales especializados en comercialización para mejorar la calidad del servicio que ofrece?

Nunca

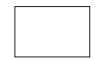

A veces

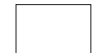

Siempre

11. ¿Forma parte de asociaciones con microempresas del mismo rubro a fin de mejorar el servicio o producto?

Nunca

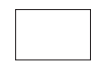

A veces

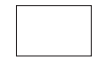

Siempre

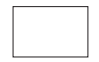

\section{ÁREA: GENERALIDADES DEL SERVICIO}

12. ¿Sus productos o servicios son iguales a los de su competencia?

SI

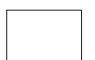

NO

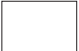

13. Si su respuesta es afirmativa, ¿brinda productos o servicios complementarios al servicio o producto que usted ofrece?

sí

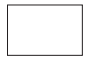

NO

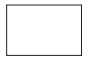


Propuesta de aplicación de la teoría CRM en las unidades productivas y comerciales del sector de confecciones...

14. Si su respuesta es afirmativa, exprese de qué manera:

- Promociones

- Descuentos

- Sorteos

- Remates

15. Considera Ud. que los servicios que brinda la plaza Gamarra son:

- Malos

- Regulares

- Buenos

- Excelentes

16. ¿Considera usted que el emporio comercial de Gamarra establezca convenio con empresas de taxis para brindar servicios de transporte a la Plaza Gamarra?

sí

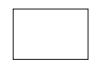

NO

17. ¿Considera Ud. que se debe efectivizar este servicio en la plaza Gamarra?

Sí

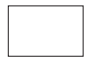

NO

18. ¿Está de acuerdo que debe brindarse un servicio de transporte a los clientes de la Plaza Gamarra desde puntos estratégicos de Lima Metropolitana?

Sí

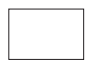

NO

19. ¿Cree usted que el nivel de servicios que ofrece Gamarra satisface las necesidades de los clientes?

sí

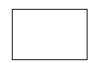

NO

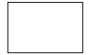

Si la respuesta es positiva ¿cuál es el nivel que usted considera?

- Muy alto

- Alto

- Medio

- Bajo

- Muy bajo

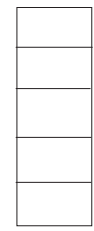

ÁREA: PERCEPCIÓN

20. ¿Considera que la Plaza Gamarra es un emporio comercial carente de modernidad y bajo nivel tecnológico?

sí

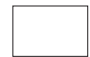

NO

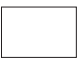


Propuesta de aplicación de la teoría CRM en las unidades productivas y comerciales del sector de confecciones...

21. ¿Qué mejoras como empresario espera ofrecer en la Plaza Gamarra?

- Mejores precios

- Calidad en los servicios, productos

- Seguridad y protección a los posibles robos

- Higiene del lugar y rapidez en el servi

- Mejor trato personal en los establecimientos

- Mayor número de servicios

- Mejor servicio de información y señalización

- Mayor formalización de los establecimientos comerciales

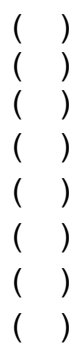

22. El personal que trabaja en su establecimiento se siente involucrado en el servicio que ofrece

sí

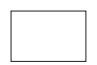

NO

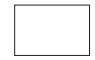

23. El trato que su personal de su establecimiento brinda a sus clientes es:

- Muy malo

- Malo

- Regular

- Bueno

- Muy bueno

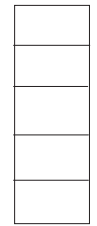

24. ¿Cómo considera la labor de la comisaría de La Victoria a fin de mejorar las condiciones de seguridad en la plaza Gamarra ?

- Muy buena

- Buena

- Regular

- Mala

- Muy mala

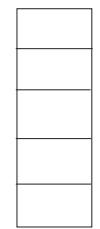

25. ¿Considera Ud. que es necesario, mayor formalización de los establecimientos comerciales para optimizar la gestión de las unidades productivas y comerciales de Gamarra?

- Muy de acuerdo

- De acuerdo

- Ni de acuerdo ni en desacuerdo

- En desacuerdo

- Muy en desacuerdo

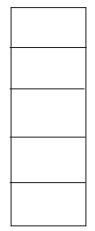

26. ¿Considera que debe ampliarse la cantidad de servicios de información en la Plaza Gamarra?

Sí

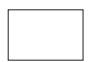

NO

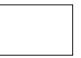


Propuesta de aplicación de la teoría CRM en las unidades productivas y comerciales del sector de confecciones...

27. ¿Considera que debe ampliarse la cantidad de señalizaciones en los establecimientos de Gamarra?<smiles>[SiH3]C1CCC1</smiles>

NO

28. ¿Sabía Ud. que la instalación de campañas de telemarketing es necesaria en Gamarra para tener acceso a los productos con mayor ventaja?

sí

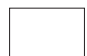

No

29. ¿Considera Ud. que el diseño de canales virtuales (comunicación electrónica, conferencias) incrementaría el interés para obtener mayor información actualizada y personalizada de Gamarra?

sí

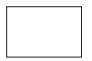

No

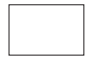

30. Considera Ud. importante la implementación de la tecnología para determinar volúmenes de compra de los clientes y factores causantes de la deserción e historial de consumo para tomar mejores decisiones y realizar acciones pertinentes de fidelización

sí

No

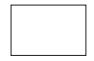


Propuesta de aplicación de la teoría CRM en las unidades productivas y comerciales del sector de confecciones...

Anexo 2

Encuesta para los clientes de la Plaza Gamarra

ÁREA: VISITA A GAMARRA

1. Durante su visita en la Plaza Gamarra, ¿qué lugares visitó?
a. Lugares de confecciones y ventas de prendas de vestir
b. Lugares como restaurantes y fuentes de soda
c. Lugares como tragamonedas, discotecas
d. Lugares como boticas y farmacias
e. Lugares como ferreterías, pinturas y plásticos.
f. Lugares como oficinas administrativas, consultorios médicos.
g. Lugares como bancos y librerías

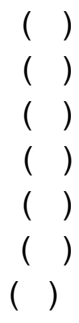

2. Si ya estuvo antes en la Plaza Gamarra, ¿su estadía fue satisfactoria?

- Totalmente satisfecha

- Satisfecha

- Ni satisfecha ni insatisfecha

- Insatisfecha

- Totalmente insatisfecha

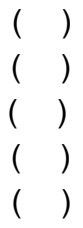

3. ¿Qué lo ofrece la Plaza Gamarra?

- Precios bajos

- Productos de calidad

- Variedad en los productos

- $\quad$ Lugares de entretenimiento

- Lugares de gastronomía variada

4. ¿Con qué frecuencia visita Ud. el emporio comercial de Gamarra.

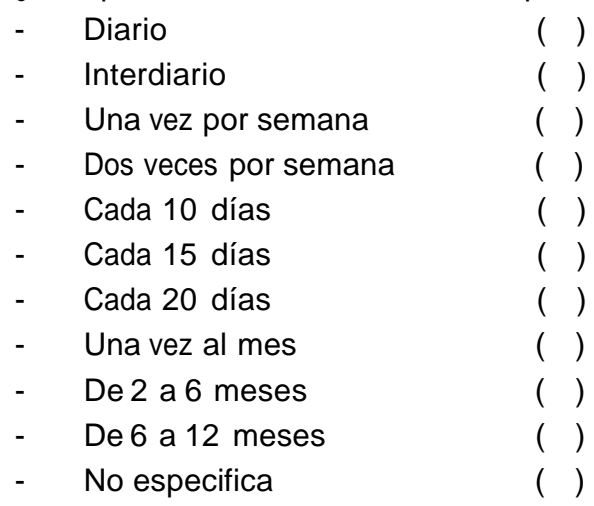

5. Desde su última visita a la Plaza Gamarra, ¿considera que los servicios han mejorado?
sí ( )
No ( ) 
Propuesta de aplicación de la teoría CRM en las unidades productivas y comerciales del sector de confecciones...

6. ¿Tiene intención de regresar a la Plaza Gamarra?

- Definitivamente sí regresaría

- Posiblemente sí regresaría

- No podría precisar

- Probablemente no regresaría

- Definitivamente no regresaría.

7. ¿En qué momento del día prefiere visitar la Plaza Gamarra?
Mañana ( )
Tarde ( )
Noche ( )

8. ¿Tiempo que permaneció en la Plaza Gamarra?
A. 1 hora ( )
B. 2 horas ( )
C. 3 horas $(\quad)$
D. + de 4 horas ( )

Si fuera la alternativa A o B, ¿cuál de las siguientes razones limitaron su estadía en la Plaza Gamarra?

- $\quad$ No tener más dinero en efectivo

- Poco transporte público seguro

- $\quad$ No tuve mayor información acerca de otros productos y servicios que ofrece la plaza Gamarra. ( )

- Lejanía del hogar

- Robos/secuestros.

9. ¿Cuál fue el nivel de expectativa de su visita a la Plaza Gamarra de los siguientes servicios?

\begin{tabular}{|c|c|c|}
\hline Lugares de & Muy bajo & $(\quad)$ \\
\hline confecciones y & Bajo & ( \\
\hline prendas de vestir & Regular & ( \\
\hline & Alto & ( \\
\hline & Muy alto & ( ) \\
\hline Lugares como & Muy bajo & ( \\
\hline restaurantes & Bajo & ( \\
\hline y fuente de soda & Regular & ( \\
\hline & Alto & ( \\
\hline & Muy alto & ( ) \\
\hline Lugares como & Muy bajo & ( \\
\hline Tragamonedas, & Bajo & ( \\
\hline Discotecas & Regular & ( \\
\hline & Alto & ( \\
\hline & Muy alto & ( ) \\
\hline
\end{tabular}


Propuesta de aplicación de la teoría CRM en las unidades productivas y comerciales del sector de confecciones...

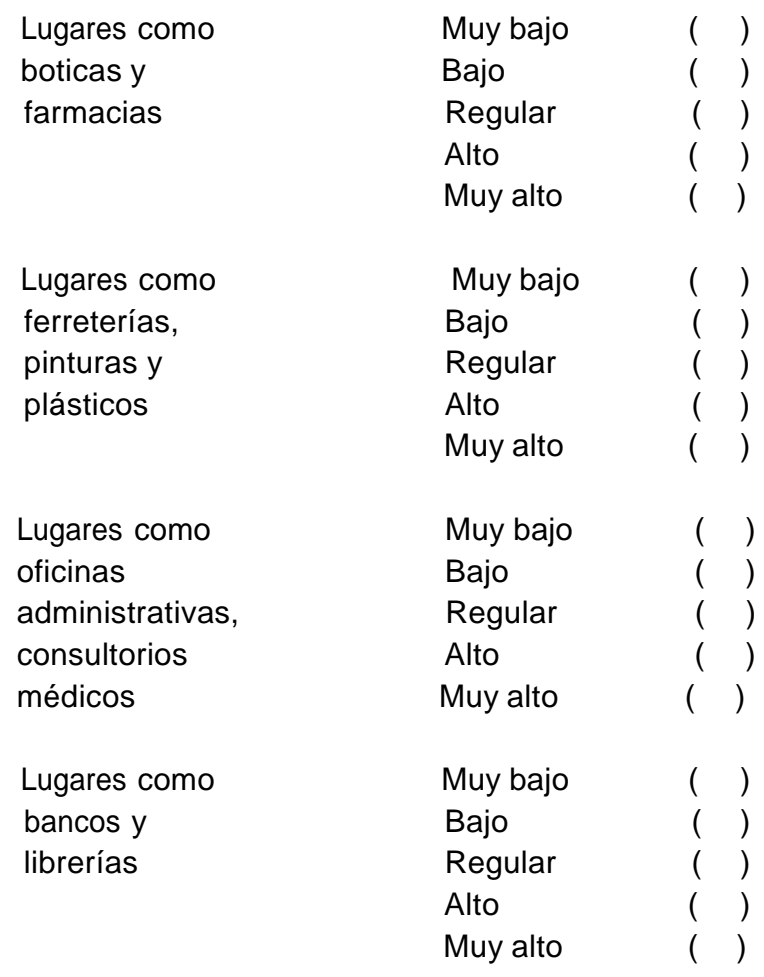

10. Realizar compras en la Plaza Gamarra

No lo recomendaría $(\quad) \quad \begin{aligned} & \text { Lo recomendaría } \\ & \text { con reservas }\end{aligned} \quad \begin{aligned} & \begin{array}{l}\text { Lo recomendaría } \\ \text { enfáticamente }\end{array} \\ & \text { a }\end{aligned}$

11. ¿Cuál es el volumen de compra que usted realiza en la Plaza Gamarra?

- De S/.5 a S/. 100

- De S/. 100 a S/. 500

- De S/. 500 a S/. 1000

- De S/. 1000 a S/ 1500

- $\quad$ Más de S/. 1500

\section{ÁREA : SERVICIOS}

12. ¿Está satisfecho con la calidad del servicio que se brinda en la Plaza Gamarra?

- Totalmente insatisfecho

- Insatisfecho

- Ni insatisfecho, ni satisfecho

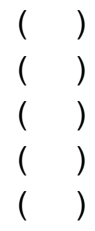

- Satisfecho

- Totalmente satisfecho

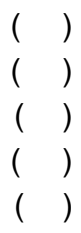


Propuesta de aplicación de la teoría CRM en las unidades productivas y comerciales del sector de confecciones...

13. ¿Recibe información sobre los servicios que ofrece la Plaza Gamarra?

sí ( ) NO( )

Si su respuesta es afirmativa, en que medios publicitarios lo recibe:

- Internet

- Radio

- Folletos

- Periódicos

- Instituciones como Prompyme, Apemipe, etc...

14. ¿Sabe Ud. que cuenta con los servicios de apoyo permanente de serenazgos y PNP?
sí ( )
NO ( )

\section{ÁREA:MODERNIDAD Y TECNOLOGÍA}

15. ¿Considera que la Plaza Gamarra es un emporio comercial carente de modernidad y bajo nivel tecnológico?
sí ( )
NO ( )

16. ¿Considera Ud. que la innovación tecnológica son necesarias en Gamarra?
sí ( )
NO ( )

17. Sabía Ud. que la instalación de campañas de telemarketing es necesaria en Gamarra para tener acceso a productos de mayor ventaja?
sí ( )
NO ( )

18. ¿Considera Ud. que el diseño de canales virtuales (comunicación electrónica, conferencias) incrementaría el interés para obtener mayor información actualizada y personalizada de Gamarra?
sí ( )
NO ( )

19. ¿Considera Ud. importante la implementación de la tecnología para determinar volúmenes de compra de los clientes y factores causantes de la deserción e historial de consumo para tomar mejores decisiones y realizar acciones pertinentes de fidelización?
sí ( )
NO ( ) 